\title{
Cancer Gene Therapy - Key Biological Concepts in the Design of Multifunctional Non-Viral Delivery Systems
}

\author{
Cian M. McCrudden and Helen O. McCarthy \\ Additional information is available at the end of the chapter \\ http://dx.doi.org/10.5772/54271
}

\section{Introduction}

The importance of gene therapy strategies for the treatment of malignancies is highlighted by the fact that there are (at the time of writing) 823 cancer gene therapy clinical trials worldwide that are actively, or have yet to begin recruiting patients (www.clinicaltrials.gov - accessed November 2012). The potential of the delivery of genetic material for therapeutic purposes has long been recognised, but to this point, has yet to be successfully translated. Strategies that have proved promising in the in vitro setting have stumbled when exposed to the complexities of the in vivo environment. Classically involving the delivery of plasmid DNA (pDNA) that encodes a therapeutic protein product, the field of gene therapy has evolved to encompass not only delivery of therapeutic DNA, but also micro- (miRNA), short hairpin- (shRNA) and small interfering RNAs (siRNA) and oligodeoxynucleotides (ODNs) [1]. Despite the evolution of the technology for altering the genotype of target cells and tissues, the problem of overcoming the biological barriers that limit the efficacies of these technologies remains. These barriers exist at both systemic and local levels. To date, the only approved nucleic acid-based treatments for clinical use are an antisense ODN for the treatment of cytomegalovirus retinitis [2], and pegaptanib sodium (Macugen), an RNA aptamer targeted against VEGF-165 and used to treat age-related macular degeneration [3]. This chapter will focus on the biological barriers faced by non-viral vectors for gene therapy, strategies that have been employed to overcome these barriers, and will conclude by documenting the state of the art technologies being used to propel non-viral gene therapies forward.

\subsection{Non-viral gene therapy}

Delivery of genetic material for therapeutic use from virus-like particles has received considerable attention, and has generated extensive knowledge. The molecular evolution of viruses 
over the aeons has produced DNA-delivering organisms of incomparable efficiency. The use of 'gutted' viruses that lack virulence properties and replicative capacity is the most efficient method of genetic material delivery [4], and modified viruses have been used extensively in gene therapy; commonly employed viruses include adenovirus, retrovirus, vaccinia virus and herpes simplex virus [5]. The allure of viral gene therapy was hindered however, when a clinical trial patient died four days after receiving adenoviral therapy for treatment of ornithine transcarbamylase deficiency [6]. The negative press that this generated, along with other disadvantages of viral gene therapy (including generation of immune response, possibility of proto-oncogene activation, production costs, and limitations in deliverable gene size) have necessitated the generation of alternative gene therapy strategies [7].

Despite some success when naked DNA has been delivered in vivo (naked pDNA has been effectively delivered to the liver in mice and rats [8] by tail vein injection), pDNA for gene therapy is conventionally delivered complexed with materials with suitable physical characteristics. pDNA's hydrophilicity and anionic nature impair the uncomplexed molecule's passage through the lipophilic plasma membrane $[1,9,10]$. Non-viral gene therapy strategies usually involve wrapping of the nucleic acid to be delivered in a protective envelope that neutralises the negative charge of the DNA. A range of compounds has been used to envelop pDNA, including cationic lipids, polymers and peptides.

Cationic lipids were among the first compounds complexed with pDNA for non-viral gene delivery. Felgner reported that N-[1-(2,3-dioleyloxy)propyl]-N,N,N-trimethylammonium chloride (DOTMA) formed lipid-DNA complexes based on the interaction between the positively charged lipid and the negatively charged phosphates of the DNA. The lipoplexes soformed were capable of delivering DNA to cells in vitro [11]. Numerous cationic lipids have since been reported to neutralise, condense and encapsulate pDNA, including dioctadecylamidoglycylspermine (DOGS) [12],[1,2-bis(oleoyloxy)-3-(trimethylammonio)propane] (DOTAP) [13] and $3 \beta\left[\mathrm{N}-\left(\mathrm{N}^{\prime}, \mathrm{N}^{\prime}\right.\right.$-dimethylaminoethane)-carbamoyl] cholesterol (DC-Chol) [14]. Variations on a theme, these lipids behave similarly to innate biological lipids [15]. The addition of co-lipids such as cholesterol and dioleoylphosphatidylethanolamine (DOPE) can improve transfection efficiency [16]. Recent developments in the field have seen a 1-palmitoyl-2-oleoyl-sn-glycero-3-ethylphosphocholine (EPOPC):cholesterol liposome with folate electrostatically-associated used to deliver HSV-tk suicide gene therapy to SCC-VII xenografts, which resulted in considerable tumour growth delay [17]. In a magnetofection method, intravenous delivery of superparamagnetic iron oxide lipid nanoparticles in combination with an Nd-Fe-B magnet placed externally in the tumour locality resulted in improved IGF-1R shRNA delivery to A549 xenografts [18].

Cationic polymers have been used to condense and deliver genetic material, including poly(l-lysine) (PLL), polyethylenimine (PEI), chitosan and polyamidoamine (PAMAM) [7]. PLL incorporated into a spider silk-based nanoparticle with a tumour-homing peptide was recently reported to deliver a luciferase plasmid to MDA-MB-231 xenografts following intravenous administration [19]. A novel triblockpoly(amido amine)-poly(ethylene glycol)-polyl-lysine (PAMAM-PEG-PLL) nanocarrier successfully delivered Bcl-2 siRNA and elicited knockdown of the same in A2780 ovarian carcinoma cells in vitro [20]. Heparin-PEI nanogels 
were used to reintroduce heparin sulphate 6-O-endosulfatase 1 (HSulf-1) to ovarian SKOV-3 xenografts, which resulted in anti-angiogenesis, induction of apoptosis and suppression of cell proliferation [21], while a PEI-poly(hydroxyethyl glutamine) (PEI-PHEG) copolymer successfully delivered pGL3 pDNA by intratumoural administration to Lewis Lung Carcinoma xenografts in C57BL/6 mice [22].

Cationic peptides that are capable of neutralising, condensing and wrapping pDNA have also been used as non-viral delivery vehicles [23]. These cell-permeating peptides were designed to interact with cell membranes similarly to viral fusion proteins. GALA, a synthetic peptide designed to interact with lipid bilayers at an acidic $\mathrm{pH}$, was observed to aid in the delivery of DNA to cells [23]. A derivative, termed KALA, through presence of positively charged lysine residues, is capable of condensing and delivering DNA unaided [24], and improved gene delivery ten-fold in hepatoma [25] and also in HEK293T and HepG2 cells [26]. The cell-penetrating peptide TAT and fusogenic peptide HA2 were used to improve pDNA delivery by gelatin-silica nanoparticles [27]. Recent developments in the field have seen the development of multi-domain peptidic biomimetic vectors tailored to overcome the various biological barriers that gene delivery vehicles encounter in vivo, including degradation by serum nucleases, endosomal entrapment and nuclear localization. One such designer biomimetic vector was used to deliver tumour-related apoptosis inducing ligand (TRAIL) [28] and inducible nitric oxide synthase (iNOS) pDNA to ZR-75-1 breast cancer cells in vitro [29].

Non-viral strategies for gene therapy have several advantages over traditional viral approaches, including reduced cost and ease of large-scale production, as well as avoidance of the virulence commonly associated with viral delivery. However, non-viral gene delivery systems suffer from lower potency of transfection ability, resultant of lower ability to traverse the various obstacles faced upon administration [7].

\section{Extracellular barriers to gene delivery}

\subsection{The skin}

The most fundamental barrier that the human body possesses is its skin. The stratum corneum is the skin's outermost layer, and provides an imposing barrier to gene delivery [30]; the densely packed cornified cells of this layer protect the body from a range of foreign material. The skin is not a commonly used route for gene therapy approaches, but it is an attractive route for local targeting of dermatological ailments [31]. However, skin nucleases, and in particular DNAse 2, active at the skin and in the stratum corneum, degrade topicallyapplied nucleic acids [32]. An appropriate and potent delivery mechanism could open the door to gene therapy strategies for the treatment of skin conditions and malignancies, including xeroderma pigmentosum (a cancer-linked disorder that has shown promise in preclinical gene therapy approaches [33]), when replacement of the defective XPC gene is in keratinocytes would be therapeutically beneficial [34].

Introduction of micron-sized pores to the skin using minimally-invasive silicone microneedles allowed for the delivery of a 'non-viral gene vector-mimicking' charged fluores- 
cent nanoparticle [35,36]. A needle-free injection device successfully delivered luciferase pDNA to porcine skin, resulting in higher protein expression than conventional hypodermic needle administration [37], while subcutaneous melanoma xenografts were targeted for gene therapy using a hybrid electro-microneedle; delivery of $20 \mu \mathrm{g}$ interleukin-12 pDNA to the skin, followed by eight $50 \mathrm{~ms}$ pulses delivering $70 \mathrm{~V} / 0.5 \mathrm{~cm}$ from the electrode to improve transfection resulted in a significant improvement in survival of tumourbearing mice [38]. Most recently, researchers from Northwestern University reported the generation of siRNA-carrying nanoparticles (spherical nucleic acid nanoparticle conjugates (SNA-NCs)) that are capable of penetrating nude mouse and human skin, whilst maintaining their RNA interference potential [36]. The nanoparticles comprise gold cores surrounded by a dense shell of highly oriented, covalently immobilised siRNA and could be delivered topically, avoiding the need for disruption of the skin. As the skin is unmolested, the authors propose that the miniscule nature of the SNA-NCs permit dermal crossing, a theory that is currently under investigation.

\subsection{Barriers to systemic gene therapies}

Needle-administered systemic therapeutics bypass the skin, but encounter further extracellular barriers before reaching their site of action. The various administration routes (intravenous, -muscular, -ocular, -nasal) present their own unique impediments to nucleic acid delivery. Intravenously- [39] and intramuscularly-administered [40] therapies are subject to nuclease degradation from the point of entry. Conversely, naked uncomplexed anti-respiratory syncytial virus (RSV) siRNA was almost as effective as that complexed with TransITTKO transfection reagent when nasally-administered in mice [41], suggesting that nasallyadministered gene therapies may not be as prone to nuclease insult. The compartmental nature of the eye, and ease of access to it simplifies avoidance of similar barriers in ocular gene therapy delivery [42]. pDNA complexed with poly(d,l-lactic-co-glycolic) acid (PLGA) and dimethyldioctadecylammonium bromide (DDAB) produced nanoparticles capable of traversing one of the most inhospitable of barriers, the gastric mucus [43]. For simplicity, this chapter will focus on the barriers faced by intravenously delivered therapies, as this route has the potential to target almost all tissues of the body.

The complexing of DNA into lipo- or polyplex nanoparticles in non-viral delivery can effectively protect the pDNA from nuclease degradation [44] (although, paradoxically, cationic and anionic lipoplexes can hinder pDNA delivery by electroporation [45]). Whilst in the circulation, however, non-viral agents can be subject to non-specific binding by serum proteins, which can result in aggregation or dissociation of nanoparticles, resultant of the generally positive charges of the nanoparticles and the negative charge of circulatory proteins [1]. Positive charge is essential to ensure interaction of the nanoparticle with its target cell, however the mononuclear phagocytic system (MPS) eliminates foreign hydrophobic particles from the circulation [7] by opsonisation. The MPS was neutralised in mice by pretreatment with polyinosinic acid (a synthetic nucleic acid strand) before therapeutic measles virus treatment; this led to competitive inhibition of the scavenging of particles by macrophages, and improved virus delivery to and efficacy at SKOV3 xenografts [46]. Aggregation 
of nanoparticles can cause embolization of microvessels, and non delivery of the therapeutic to target [1].

The differential in ionicity between gene therapy formulation and the extracellular space poses another obstacle for nanoparticles, which can lead to colloidal instability [44]. The issue of non-specific interaction between nanoparticles and plasma proteins has been addressed by the coupling of hydrophilic molecules to the nanoparticle. The most commonly employed candidate is poly(ethylene glycol) (PEG), whose anionicity has led to reduced aggregation and improved transfection ability [47]. PEG has been incorporated into a myriad of non-viral gene therapy strategies. Recently, polyacridine peptide nanoparticles were PEGylated and found to persist in the mouse circulation for up to nine hours, compared to non-PEGylated nanoparticles, which were inactive within five minutes [48], while biodegradable dextran nanogels were PEGylated and analysed for their siRNA delivering prowess [49]. Particulate gene therapies are also subject to entrapment by the mononuclear phagocyte system (reticuloendothelial system - RES), when they are captured and held in the spleen or liver [50], which was responsible for the inactivation of adenoviral vectors that have been used as viral gene therapeutics [51]. Avoidance of non-specific biomolecular interaction, referred to as 'stealth' [1], is a prerequisite for successful gene delivery. Functionalisation of non-viral gene therapies with agents such as PEG to facilitate RES avoidance will be discussed in subsequent sections.

Assuming a gene therapeutic persists in active form in the circulation and the target tissue is reached, extravasation from the circulation is imperative. The architecture of normal vasculature ensures that transport of macromolecules out of the circulation is difficult. One characteristic of tumour vasculature, however, is its propensity to leakiness, an attribute that can be exploited by gene therapies. It is unsurprising that siRNA lipoplexes that target RAN GTPase were delivered more effectively, and evoked more impressive anti-tumour effects in highly vascularised xenografts than in xenografts with poorer vascularity [52]. The leaky vessel phenomenon, known as the enhanced permeability and retention (EPR) effect, has been utilised to enable the delivery of pDNA-containing particles in various malignancies [53]. The utilization of EPR will be further discussed below. The angiogenic tumour vasculature was itself targeted in a murine dorsal air sac assay; siRNA targeting Ago2 was complexed into cationic liposomes and intravenously administered. The authors successfully delivered the interfering RNA to the angiogenic vessels, and reported tumour regression, presumed to be resultant of anti-angiogenesis in their model [54].

Perhaps the most intimidating vascular obstacle that a gene therapy can face is the bloodbrain barrier, where tight junctions between endothelial cells of the capillaries limit the passage of molecules much more than at other capillary sites in the body. One of the most exciting techniques available to the gene therapy researcher is the use of ultrasound-targeted microbubble destruction (UTMD); nucleic acid contained within a gas-filled microbubble is administered, before exposure to ultrasonic waves at a frequency that exceeds the resonance frequency of the microbubbles, causing their destruction and leading to increased capillary and cell membrane permeability [55]. This technology was used to deliver pDNA for 
the green fluorescent protein (GFP) reporter gene across the mouse blood-brain barrier [56], and presents new possibilities for overcoming this most daunting of circulatory barriers.

\subsection{Cellular barriers to gene delivery}

\subsubsection{The cell membrane and endocytosis}

Specific targeting of gene vectors to ensure delivery to the target tissue will be discussed in a subsequent section. The nanoparticle's nucleic acid cargo determines the site to which delivery is required; plasmid DNA must be delivered to the nucleus to affect transcription, while siRNA need only reach the cytoplasm to interfere with translation [57]. The most elemental impediment to entry into the animal cell is the lipid bilayer membrane. The cell membrane can be breached using physical means in certain circumstances to allow delivery of naked pDNA. These methods include electroporation (local destabilization of the cell membrane using an electric pulse), sonoporation (membrane destabilization using ultrasound) or laser irradiation (introduction of transient pores in the membrane using a lens-focussed laser beam). The application of these methods is limited, however, by inaccessibility to most tissues [58].

Condensation and neutralization of nucleic acids into nanoparticles abrogates the two fundamental properties of pDNA that preclude its cellular entry, namely its large size and negative charge [1]. Particles of excessive size can aggregate and cause embolization of narrow capillaries, as mentioned above. Nanoparticles for gene delivery tend to be sub-200 nm for this reason. However, in vivo delivery of fluorescently labelled liposomes of up to $400 \mathrm{~nm}$ diameter has been reported [59]. Particle size also appears to dictate the pathway that performs internalization of complexes; $200 \mathrm{~nm}$ particles have entered cells by clathrin-dependent routes, $300 \mathrm{~nm}$ particles by caveolae-mediated pathways [7]. Optimization of the net charge (or zeta/ $\zeta$ potential) of delivery vehicle/nucleic acid complex of lipid/polymer/ peptide and pDNA complexes is achieved by the electrostatic interaction between the negatively charged phosphate residues present in the pDNA and the positively charged nitrogen in the vehicle. The net charge of the resultant particle can be increased by increasing the vehicle (nitrogen) to pDNA (phosphate) ratio (known as N:P ratio) [1]. The negative charge of serum proteins can thwart the therapeutic potential of nanoparticles; this can be overcome by increasing the N:P ratio of complexes above that sufficient to condense the pDNA. Altering the net charge of the nanoparticles can significantly alter the array of plasma proteins that interact with the particles. Similar liposomal particles with charges of $-9.0,-11.4$ and -27.4 were incubated with human plasma, and the interacting proteins were identified; 117 proteins were found bound to particles of all three charges, while 12, 6 and 15 plasma proteins interacted uniquely with the three particle charge types respectively [60]. Kim and coworkers reported that hyperbranched polysiloxysilane nanoparticles with a moderate positive charge $(46 \mathrm{mV})$ were more efficient gene delivery agents than analogous particles with a high positive charge $(64 \mathrm{mV})$ [61]. Clearly, nanoparticle size and charge are parameters that require optimization for appropriate cell membrane breaching. Phosphoniumbased vectors (as opposed to nitrogen-based) are also being explored for their gene delivery 
potential; preliminary studies have revealed that phosphonium-based vectors condensed DNA at lower charge ratios than corresponding nitrogen-based vectors [62].

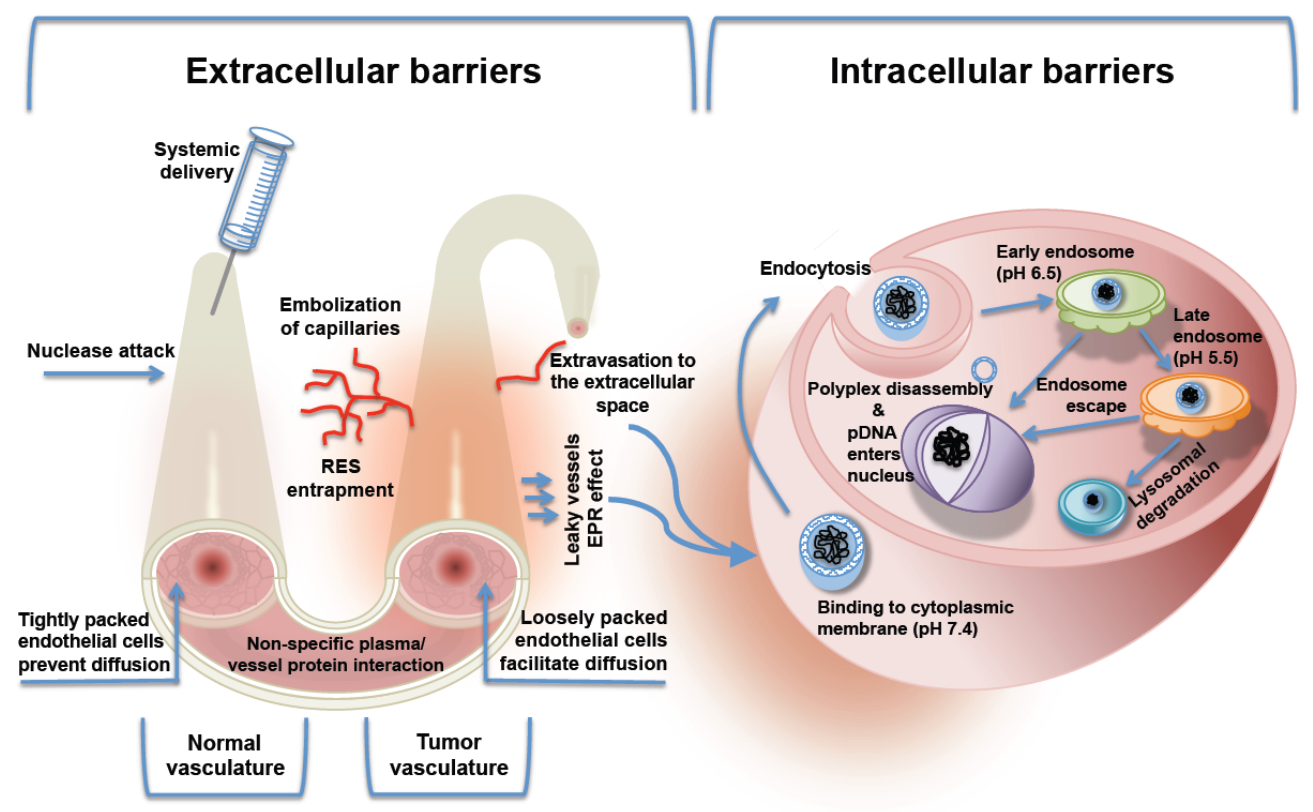

Figure 1. Summary of the extra- and intracellular barriers faced by non-viral gene therapies following systematic delivery. Based on [1].

Electrostatic interaction between the cationic nanoparticle and the anionic cell membrane that facilitate association between the cell and nanoparticle was assumed to result in endocytosis of the nanoparticle, although the machinery of internalization appears to be materialand cell type-dependent. Endocytotic access to cells is by pinocytosis in the majority of cases, rather than by phagocytosis [9]. A mechanism of endocytosis was clarified by Payne and colleagues, who followed the intracellular trafficking of PEI- and Lipofectamine ${ }^{\mathrm{TM}}{ }_{-}$-complexed nucleic acids in mammalian cells, and reported that endocytosis relied upon cell surface heparin sulphate proteoglycans (HSPG) and was dependent on dynamin- and flotillin, rather than clathrin- and caveolin-dependent mechanisms [63]. On the other hand, nanoparticles formed from pDNA complexed with PEG-CK $\mathrm{CK}_{30}$ were endocytosed after interaction with cell surface nucleolin, a process that was reliant on the activity of lipid rafts [64]. A recent study reported by a team at the University of Groningen very elegantly showed lassoing of PEI- and Lipofectamine ${ }^{\mathrm{TM}}$-complexed pDNA by syndecan- and actin-rich filaments of HeLa cells, presumed to be filopodia and retraction fibers; the nanoparticles then 'surf' along the filopodia, or the filopodia are retracted toward the cell body, thereby facilitating HSPG-mediated endocytosis [65]. 


\subsubsection{Endosomal escape}

The result of endocytic cellular entry is endosomal entrapment. Endosomes are a range of membrane-bound organelles that include early, late and recycling endosomes that are responsible for the short-term storage and sorting of endocytosed materials, including macromolecules and pathogens (including viruses). Once material is endocytosed, it is either evicted from the cell by the recycling endosome, or the complex process of endosome maturation ensues, late endosomes fuse with lysosomes, and active degradation of endosome cargoes occurs [66]. Macromolecules that are unable to escape the endosome are bound for lysosomal degradation.

The mechanism of endosomal escape by non-viral vectors is dependent on the complexing material used. Cationic lipids appear to interact with the anionic endosomal membrane, resulting in ion pair formation and consequent transformation to inverted hexagonal phase $\left(\mathrm{H}_{\mathrm{II}}\right)$, causing disruption of the endosomal membrane. Alternatively, an inversion of the endosomal membrane as a result of electrostatic interactions has been proposed, which would instigate nucleic acid cargo being deposited in the cytoplasm. When polymeric materials are used to complex pDNA, the polymers themselves absorb protons in the endosome (protonsponge effect), leading to chloride ion influx, increased osmotic pressure and water flow into the endosome, resulting in endosome rupture [7].

The fusogenic lipid DOPE is frequently used as a co-complexing agent due to its inherent ability to facilitate endosomal escape; conformational change from lipid bilayer to an inverted hexagonal structure is triggered by the sub-physiological $\mathrm{pH}$ of the endosome, and causes endosomal membrane disruption and escape of nucleic acid cargo [67]. Viral membrane proteins have provided inspiration for the non-viral gene delivery researcher. Influenza viruses escape the endosome with the help of hemagluttinin A2 (HA2), while the adenoviral protein, penton, assists adenovirus endosome escape. Glycoprotein $\mathrm{H}$ from herpes simplex virus induced 30-fold improvement of transfection by lipoplexes in human cell lines [68]. Conformational changes of these proteins consequential of the acidic environment in the endosome facilitate viral particle escape from the endosome; the more hydrophobic conformation that they adopt at low $\mathrm{pH}$ permits membrane fusion and disruption [1].

Synthetic fusogenic peptides are increasingly being used to improve transfection in non-viral systems. The conformational status of GALA is responsive to $\mathrm{pH}$, adopting alpha-helical status in acidic environments, and in that sense, mimics the endosomal escape route favoured by viruses [69]. Derivatives of GALA such as GALAdelE3, YALA [70], and KALA [24] have all shown promise as endosome escaping agents. Similarly, two endosomal escape peptides, INF7 and H5WYG, improved endosome escape of PEG-based vectors by up to 100-fold [71].

\subsubsection{Nuclear envelope penetration}

The final obstacle faced by pDNA gene therapies is the nuclear envelope, a barrier punctuated with nuclear pores impermeable to molecules greater than $70 \mathrm{kDa}$, or roughly $10 \mathrm{~nm}$ in diameter [72]. Liposomal fusion with the nuclear membrane that facilitates direct cargo 
transfer from vector to nucleus has been reported [73]. Mitotic division temporarily disrupts the nuclear membrane's barrier properties, which can allow pDNA transgene entry [9]. The nuclear pores can be more actively targeted for penetration by the use of nuclear localization signalling (NLS) peptides or DNA targeting sequences (DTS). NLSs are short clusters of basic amino acids (such as lysine) that bind to importins, receptors that facilitate cytoplasmnuclear transport [74]. Active transport of macromolecules through nuclear pore complexes causes expansion of the pores to approximately $30 \mathrm{~nm}$ in diameter [75]. The nuclear localization peptide SV40 from Simian virus 40 was used to improve the delivery of luciferase genecarrying liposomes to neuroblastoma cells [76], while NLSs from adenovirus E1a, the transcription factor c-myc, mouse FGF3, and the DNA repair protein PARP have all been used to guide transgene delivery to the nucleus [74]. Some of the recently employed nuclear envelope penetration strategies are summarised in Table 1.

\section{Evading the immune system}

As mentioned previously, although viruses are masters of nucleic acid delivery, alternative delivery mechanisms are being sought to avoid the pitfalls associated with viral systems. Fundamentally, viruses remain foreign pathogens, agents that the human body has evolved to protect itself from. Of the commonly employed viral vectors, adenoviral, adenovirus-associated vectors and lentivirus vectors all produce immune responses in mice and humans, with antibodies often being produced against both the packaging vector as well as the transgene product. Exposure to viral particles triggers the adaptive immune response. Pinocytosis of viral particles by immature dendritic cells elicits maturation of the dendritic cells into mature antigen-presenting cells that present antigens in major histocompatability complexes (MHCs). Activation of $\mathrm{T}$ cells by antigen presentation leads to both the destruction of the antigen-presenting cells, and the recruitment and activation of B cells, responsible for antibody production [84].

Attempts to avoid provocation of immunologic responses have been made by the viral gene therapist that include deletion or nullification of viral coding genes and elimination of pathogenic genes, or use of targeting strategies to ensure avoidance of the immune cells. Additionally, pharmacological immunosuppression has been used extensively to avoid the neutralization of various viral gene therapy strategies [85].

\subsection{DNA-mediated immune responses}

It is generally accepted that non-viral gene therapy strategies elicit fewer immune responses than their viral counterparts, although certain facets of non-viral complexes mark them as targets for immune system intervention [86]. An early report into immune responses induced by non-viral gene therapy revealed cytokine induction (TNF $\alpha$ and IL-1 $\beta$ ) by PEI/DNA complexes; the extent of immune induction was determined by the route of delivery, aerosol proving less detrimental than intravenous [87]. In mice, lipoplex administration evoked complement activation and induction of IFN- $\gamma$, TNF- $\alpha$, IL-6, and IL-12. These effects 


\begin{tabular}{|c|c|c|c|c|}
\hline NLS & Sequence & Summary & Result & Ref \\
\hline TAT & $\begin{array}{l}\text { Ac-GCGYGRKKRRQRRRG- } \\
\mathrm{NH}_{2}\end{array}$ & $\begin{array}{l}\text { PEG-based vector with } \\
\text { DNA binding peptide }\end{array}$ & $\begin{array}{l}\text { Up to } 15 \text {-fold increase in } \\
\mathrm{CHO} \text { cell transfection }\end{array}$ & {$[77]$} \\
\hline $\begin{array}{l}\text { NLS-1 } \\
\text { NLS-2 } \\
\text { NLS-3 }\end{array}$ & $\begin{array}{l}\text { DPKKKRKV } \\
\text { DPKKKRKVDPKKKRKV } \\
\text { DPKKKRKVDPKKKRKV- } \\
\text { DPKKKRKV }\end{array}$ & $\begin{array}{l}\text { Inclusion of NLS peptides } \\
\text { in Lipofectamine } \\
\text { liposomes for transfection } \\
\text { into human and rat } \\
\text { mesenchymal stem cells }\end{array}$ & $\begin{array}{l}\text { Roughly two-, four- and } \\
\text { six-fold enhancement of } \\
\text { luciferase expression } \\
\text { respectively }\end{array}$ & [78] \\
\hline I-NLS & lodinated-PKKKRKV & $\begin{array}{l}\text { lodinated NLS was } \\
\text { complexed with pDNA } \\
\text { and PEI. Luciferase } \\
\text { transfection was assessed } \\
\text { in MCF-7 breast cancer } \\
\text { cells }\end{array}$ & $\begin{array}{l}\text { 130-fold improvement in } \\
\text { transfection compared to } \\
\text { absence of NLS. Iodination } \\
\text { improved nuclear } \\
\text { localization }\end{array}$ & [79] \\
\hline $\begin{array}{l}\text { Human surfactant } \\
\text { protein C promoter }\end{array}$ & $\begin{array}{l}318 \text { nucleotides PCR } \\
\text { amplified from genomic } \\
\text { DNA }\end{array}$ & $\begin{array}{l}\text { Sequence cloned into } \\
\text { promoterless plasmid and } \\
\text { microinjected into } \\
\text { cytoplasm of MLE-12 cells. }\end{array}$ & $\begin{array}{l}\text { Fluorescent in situ } \\
\text { hybridization revealed } \\
\text { nuclear localization in } \\
25-30 \% \text { of injected cells } \\
\text { compared to control (0\%). } \\
\text { Specific to alveolar type II } \\
\text { epithelial cells }\end{array}$ & [80] \\
\hline $\begin{array}{l}\text { Triamcinolone } \\
\text { acetonide (TA) }\end{array}$ & N/A & $\begin{array}{l}\text { TA was conjugated to PEI } \\
\text { (various molecular } \\
\text { weights) and nuclear } \\
\text { localization determined }\end{array}$ & $\begin{array}{l}\text { Low molecular weight } \\
\text { PEI/TA efficiently targeted } \\
\text { the nucleus }\end{array}$ & [81] \\
\hline Dexamethasone & N/A & $\begin{array}{l}\text { Polyplexed (PEI) with } \\
\text { pLuciferase }\end{array}$ & $\begin{array}{l}10-100 \text {-fold increase in } \\
\text { transfection efficiency }\end{array}$ & [82] \\
\hline $\begin{array}{l}\text { Trans- } \\
\text { cyclohexane-1,2- } \\
\text { diol }\end{array}$ & $\mathrm{N} / \mathrm{A}$ & $\begin{array}{l}\text { Amphipathic alcohol that } \\
\text { collapses nuclear pore } \\
\text { cores allowing } \\
\text { macromolecule uptake }\end{array}$ & $\begin{array}{l}\text { Improved Lipofectamine } \\
2000 \text {-mediated gene } \\
\text { transfection to } 293 T \text { cells } \\
\text { in vitro, but was not } \\
\text { reproducible in vivo }\end{array}$ & [83] \\
\hline
\end{tabular}

Table 1. Recent strategies employed to aid the delivery of non-viral gene therapies to the nucleus.

were independent of N:P ratio or the cationic lipid complexed with the pDNA [88]. Although observed immune responses tend to be dose-dependent, dose reduction to avoid immune induction consequently also lessens the transfection ability of the complexes, stressing the narrow therapeutic index of non-viral gene therapies [89].

It is well established that immune responses in non-viral therapies is resultant of the presence of unmethylated CPG motifs in the bacterial backbone of the plasmid. In mammals, roughly $75 \%$ of $\mathrm{CpG}$ motifs are methylated to $5^{\prime}$-methycytosine, whereas in bacteria they are usually unmethylated [89]. Recognition of unmethylated CpG motifs by Toll-like receptor 9 on immune cells causes activation of mitogen-activated protein kinases and NF- $\kappa B$ [90]. As 
well as eliminating an immune response, evidence exists to suggest that removal of unmethylated CpG motifs can increase the duration of transgene expression [91,92]. PEI-based delivery of CpG-rich pDNA was associated with a reduction in lung compliance, while delivery of CpG-diminished pDNA was not [93]. Furthermore, methylation of CpG motifs in pDNA largely reversed the immunostimulatory activity of lipoplexes and polyplexes in C57BL/6 mice [94].

Numerous strategies have been investigated to abrogate immune responses upon non-viral gene therapy administration. Liu and colleagues encapsulated various anti-inflammatory agents into DOTAP/pLuciferase liposomes, and termed the resultant complex a 'safeplex'. Safeplexes carrying dexamethasone, prednisone, indomethacin, tetrandrine and gliotoxin inhibited TNF $\alpha$ expression compared to that seen in the absence of anti-inflammatory. Importantly, the complexing of dexamethasone into the safeplex did not affect the complex's ability to deliver its pDNA cargo [89]. Delivery of oligonucleotides to inhibit cytokine $(\mathrm{NF} \kappa \mathrm{B})$ translation using non-viral carriers has also been proposed as a mechanism of counteracting the host's immune response to non-viral therapies [95].

Lipid-protamine-DNA complexes (LPDs) were used to deliver a PCR amplicon of the luciferase gene rather than a bacterial plasmid containing the luciferase gene. Luciferase translation was as efficient from the PCR amplicon as from the plasmid when both were complexed with LPD, but the immune response evoked by the PCR fragment complex was three-fold less potent than that evoked by the plasmid complex (determined by TNF $\alpha$ and IL-12 expression) [96].

The immune response can be avoided by the removal of unnecessary bacterial DNA that contains the immunological CpG motifs, bacterial origin of replication, as well as genes for plasmid antibiotic resistance that are not required for transgene expression. First reported in 1997, minicircles are gene delivery vehicles that lack prokaryotic nucleic acid, and were produced by the thermo-responsive activity of $\lambda$ integrase [97]. Minicircles were more potent reporter gene deliverers than their parental pDNA in melanoma and colon carcinoma cell lines by lipofection and electroporation [98]. Minicircles complexed with PEI also delivered the GFP gene more potently than similarly complexed pDNA [99]. The potency of minicircles has been improved by tethering minicircle liposomes to the TetR nuclear targeting device [100].

A further improvement on the immunologically inert minicircles has recently been mooted. Tightly-wound miniknot vectors are the result of DNA minicircle treatment with DNA topoisomerase II, and are proposed to be more resistant to physical damage (strand breaks) that can linearise (thereby reducing/removing efficacy) pDNA and minicircles. DNA delivery methods such as aerosol inhalation, jet-injection, electroporation, particle bombardment and ultrasound DNA transfer can subject DNA to stresses that might cause damage [101].

\subsection{Carrier-mediated immune responses}

It is important to note that immune responses to non-viral gene therapy are not solely resultant of bacterial CpG motifs. An impressive study from Kyoto University highlighted the 
immune responses that can be generated by liposomes. Using CpG-free pDNA in lipoplexes, the authors demonstrated activation of IFN $\beta$, TNF $\alpha$ and IL-6 in macrophages from TLR9 knockout mice. The extent of the immune response (as determined by in vitro cytokine induction) was dependent on the cationic lipid content of the complex. The reactions elicited by the cationic lipids can be summarised as Lipofectamine $2000>$ Lipofectamine Plus > DOTMA/DOPE > DOTMA/cholesterol [102]. The inertness of DOTMA/cholesterol as delivery vehicle was supported further in vivo, when CpG-free pDNA lipoplexes provoked no IL-6 or IFN $\beta$ induction after intravenous injection in mice [103]. The targeting of nucleic acid cargoes to specific cells/tissues (to be discussed shortly) could also remedy the immune response by preventing the transfection of non-target cells, and in particular, the antigen-presenting cells [85].

The continuing evolution of the non-viral gene therapy field has led to the development of transposon-based delivery strategies, including Sleeping Beauty, Tol2, and piggyBac. These systems appear to deliver DNA as efficiently as viruses, and provoke extended transgene product expression, whilst maintaining the low immunogenicity and other risk factors associated with viral gene delivery [104]. It is anticipated that the momentum of non-viral gene therapy research will lead to the development of vehicles and cargoes that will rival the viral gene therapy field.

\section{Targeting in non-viral systems}

The optimal gene delivery vector will protect its payload from degradation in the circulation, enable extravasation from the bloodstream, traverse cellular membranes, facilitate endosomal disruption to deliver the payload to either the cytoplasm, or if necessary, transport to the nucleus. The optimal vector should also be non-immunogenic, as discussed above. Design of such vectors obviously presents a huge challenge. Furthermore, for vectors that accomplish extra- and intracellular barrier and immune system avoidance, there is the added layer of complication that targeting presents. Frequently in cancer studies, the payload to be delivered is a therapeutic designed to over-express a protein or knockdown a gene to manifest an anti-cancer effect. In order to spare normal tissue damage, widespread toxicity, and to achieve a clinically viable therapeutic product, targeting has become an essential in the quest for a perfect vector.

\subsection{Enhanced permeation and retention effect}

Exploitation of the tumour microenvironment presents an obvious option in the targeting strategies employed by many delivery systems. The enhanced permeation and retention effect (EPR), which was mentioned briefly above, is a phenomenon whereby there is defective architecture in blood vessels, extensive angiogenesis, increased vascular permeability and an impaired function of the mononuclear phagocytic system [105-107]. The consequences of these tumour-specific physiological changes is that macromolecules $>40 \mathrm{kDa}$ selectively 'leak' out of the blood vessels and extravasate into the interstitial tumour tissue $[108,109]$. 
Particle size is an important factor for utilizing the EPR effect. Studies have shown that nanoparticles up to $400 \mathrm{~nm}$ in diameter can permeate across tumour vessels [59,110]. However, circulation times can also play a key role in successful tumour transduction, with a minimum of $6 \mathrm{~h}$ required for the EPR effect to occur [111]. The EPR effect has been exploited not only in chemotherapy drug design but also in gene delivery. In one such example, polyglycerolaminne (PG-Amine) dendrimers were complexed with siRNA and delivered intravenously to mice bearing luciferase tagged mammary tumours; after $24 \mathrm{~h}$, there was a $69 \%$ reduction in luciferase activity [112]. The authors also reported that there was clear evidence of accumulation of the complexes in the tumours but not in any other organs, which can be attributed to the EPR effect. In order for continuous knockdown of luciferase, it was determined that injections would be needed every four days [112].

There are however, a number of problems if the EPR effect is the sole mechanism for targeting in cancer gene therapy. One such problem is tumour size. Tumours that are larger than 1 $\mathrm{cm}$ in diameter develop hypoxic regions that are characterised by a lack of blood vessels, therefore the EPR effect becomes redundant in these resistant regions. Evans blue dye and albumin were used to generate a synthetic macromolecule delivery of which showed that although selective, in tumours larger than $3 \mathrm{~cm}$, the dye accumulated solely in the peripheral regions and not in the central core [113]. One method to increase the EPR in solid tumours is through the use of nitric oxide donors in combination with macromolecular delivery. Endogenous nitric oxide (NO) has an effect on blood flow, angiogenesis and metastatic potential [114-116]. From a therapeutic perspective there are conflicting reports as to whether it is better to enhance or inhibit nitric oxide within tumours [117]. From an enhancement perspective, studies within our own group using iNOS (inducible NO synthase) gene therapy have shown the cytotoxic and radio-chemo sensitizing affects through the generation of $\mu \mathrm{M}$ levels of NO [118,119]. The controlled generation of high levels of nitric oxide as the gene therapy has several anti-cancer advantages, including a genotoxic effect through oxidation, deamination and alkylation of DNA, reduction of the efficiency of DNA repair proteins such as Poly ADP Ribose Polymerase, inhibition of the transcription of hypoxia inducible factor and the anti-apoptotic factor NF-kB which reduces many other pro tumourigenic factors such as MMP1, 3, 9, VEGF, survivin and BCL2 [120]. Derivatives of NO such as peroxynitrite $(\mathrm{ONOO})$ have also been shown to potentiate the EPR effect. $\mathrm{Wu}$ and colleagues showed that this was also linked to activation of MMPs, which are known to enhance vascular permeability and angiogenesis through the degradation of matrix proteins [121]. One of the main ways of enhancing the EPR effect is through NO donors, which have been utilised in combination with chemotherapy drugs. For example nitroglycerin has been delivered with vinorelbine and cisplatin in patients with non-small cell lung cancer in a randomised phase II trial. Results showed a response rate of $73 \%$ in those patients that received the nitroglycerin plus chemotherapy, compared to $42 \%$ in the chemotherapy only arm. The improved effects were attributed to the known anti-cancer effects of NO and an improvement in drug delivery to the tumour tissue, i.e. the EPR effect [122]. With respect to gene therapy, the delivery of the iNOS gene would most certainly enhance the EPR effect in solid tumours although consideration must be given to the amount of NO generated. As gene expression is dependent on successful nuclear transport of the plasmid, it would be very difficult to pre- 
dict and indeed control. With NO gene therapy, it is therefore essential to target the expression of the gene to the target tissue to gain the maximum therapeutic benefit.

Another problem in EPR targeting comes about with what is commonly termed the 'PEG dilemma'. This is essentially a trade-off between circulation time and efficacy of nucleic acid delivery. Many nanoparticles are PEGylated to increase circulation time, avoid clearance by the reticuloendothelial system (RES) and evade an immune response. As previously stated, if the EPR effect is to be exploited in solid tumours, a long circulation time is needed and PEG represents a possible solution. However, the physiochemical properties of many delivery systems are altered when PEG is introduced; this is particularly the case when the cargo is nucleic acids such as siRNA or DNA. In order for nucleic acids to be successful they must be delivered to the correct intracellular destination. PEG not only reduces the overall charge of the nanoparticles, which in turn lowers the cellular uptake, but also impairs disruption of the endosome. Therefore if PEGylation is to be used to enable EPR targeting, novel systems must be developed that can overcome the intracellular barriers to effective nucleic acid delivery.

\subsection{Targeting ligands}

One method of targeting is via the incorporation of targeting ligands that bind to cell-surface receptors. This approach is dependent upon possession of the knowledge of which receptor or combinations of receptors are hyperactivated on the cancer cell surface. One such example is the asialoglycoprotein receptor (ASGPr) which, although present on the surface of normal hepatocytes, is overexpressed in hepatocarcinoma cells. The ligand asialofetuin has been attached to a novel lipopolymeric nanoparticle to deliver the immunostimulatory IL-12 cytokine in the treatment of hepatocellular carcinoma. Following intratumoural administration of the targeted nanoparticles, the authors showed survival in $75 \%$ of mice treated with targeted nanoparticles compared to $38 \%$ in the non-targeted nanoparticles. This indicates that the presence of the ASGPr targeting ligand improves intracellular internalization via receptor-mediated endocytosis. Following systemic delivery of either nanoparticle type, luciferase expression in the liver and lungs was assessed. Luciferase expression was 10 -fold higher in the livers of those mice that received targeted nanoparticles. However, there was also gene expression in the lung with no significant differences between targeted and non-targeted nanoparticles which indicates that further formulations may be necessary, and that evaluation of gene expression in all the organs is necessary to confirm appropriate targeting [123].

Another useful targeting ligand for cancer gene therapy is transferrin. Transferrin is overexpressed in many malignancies including breast, bladder and lung [124-126]. The differential expression of the transferrin receptor and its extracellular location make it an ideal target for systemic targeting. Systemic delivery of transferrin covalently linked to polyethylenimine has not only shown effective tumour targeting in vivo, but it can also shield the positive charge of the nanoparticles [127]. Studies by Kircheis showed that a lower molecular weight of PEI was less toxic and that the incorporation of $25 \%$ of the negatively charged lipophilic transferrin ligand gave an almost neutral zeta potential with a significant reduction in aggregation of erythrocytes. In vivo this translated into lower toxicity, one log greater gene ex- 
pression than transferrin-free nanoparticles and a 'shielding' effect to bypass organs such as the lung and target the tumour [127].

Identification of overexpressed receptors can also lead to the development tumour targeting peptides. Using phage display methods, the T7 peptide (HAIYPRH) was identified and shown to specifically bind to the human transferrin receptor, with competitive studies indicating that T7 bound at a different site to transferrin [128]. This T7 peptide has recently been utilised for targeted co-delivery of the chemotherapy drug doxorubicin (DOX) together with the human TRAIL gene (Tumour necrosis factor Related Apoptosis-Inducing Ligand) to target gliomas which are known to overexpress the transferrin receptor [129]. DOX was conjugated with a $\mathrm{pH}$ linker (for endosomal release) to T7-modified dendigraft poly-L-Lysine dendrimers which then condensed the pORF-hTRAIL DNA [129]. In vitro and in vivo evaluations revealed targeting via the transferrin receptor and accumulation of the nanoparticles in gliomas following systemic delivery with a synergistic effect. In addition, the targeted T7 nanoparticles induced much less off site toxicity while inducing a significant anti-tumour effect [129].

Other targeting ligands of note include the epidermal growth factor receptor that is upregulated in a number of solid tumours such as breast, prostate, colorectal, and ovarian [130]. Although some anti-cancer strategies are designed to prevent EGFR activation via small molecule inhibitors such as gefitinib or antibodies such as Cetuximab [131], an alternative is to exploit the differential expression of EGFR. Thiol functionalisation to attach the mouse EGF ligand to PEGylated branched PEI (25 kDa) has shown excellent in vivo targeting to hepatocellular carcinoma. Biodistribution studies illustrate quite clearly that there is significantly more expression of the luciferase gene in both Huh-7 and HepG2 HCC tumours compared to other organs following intravenous injection of the complexes [132]. The authors also found that any distribution of the DNA to the liver was exclusively in the Kupffer cells and not the epithelial cells, indicative of degradation.

The EGF-PEG-PEI system has also been used to selectively deliver synthetic double stranded RNA (poly IC) [133]. Typically dsRNA is found in virally infected cells and an associated response involves the induction of apoptosis and recruitment of inflammatory cytokines $[134,135]$. Delivery of poly IC with PEI $_{25}$-PEG-EGF killed up to $85 \%$ of EGFR-over-expressing glioblastoma multiform cells in vitro via apoptosis after 1 hour [133]. This cytotoxic effect was significantly enhanced when the PEI was partially replaced with a PEI-Mellitin conjugate, which improved endosomal disruption, enabling greater delivery of the dsRNA to the cytoplasm. In addition, the intratumoural delivery of (poly IC) PEI-PEG-EGF+PEI-Mel complexes completely eradicated the intracranial tumours for more than 1 year [133]. Further studies have revealed that with further formulation of the delivery vehicle (Linear PEI-PEG $2 \mathrm{kDa}-\mathrm{EGF}$ ), systemic delivery of poly IC can significantly reduce A431 tumour growth in vivo [136]. Similar to transferrin, polypeptides for EGFR have been isolated and used effectively in cancer gene therapy. Phage display revealed an 11 amino acid sequence (YHWYGYTPQNVI) termed GE11 that has shown specificity to the EGFR after both in vitro and in vivo studies [137]. Furthermore, when the GE11 peptide was conjugated to PEI and compared with EGF-PEI, it was found that the latter enhanced mitogenic activity, which is clear- 
ly undesirable in the cancer environment. The authors indicate that due to this lack of mitogenic activity, the GE11 ligand is safer in vivo, and delivery of the luciferase gene intravenously revealed an 18-fold increase in luciferase expression in human hepatoma SMMC-7721 tumours compared to non-targeted PEI [137].

The fibronectin attachment protein of mycobacterium has also been utilised as a targeting ligand to the fibronectin molecule on epithelial cell membranes [138]. The Fab receptor was conjugated to chitosan-DNA nanoparticles and delivered via an air jet nebuliser to enhance gene expression in the lung epithelium. Again using the luciferase reporter gene, studies revealed that there was a 16-fold increase in gene expression over the non-targeted chitosan nanoparticles [138]. Another example of exploitation of differential expression is in glioma brain capillary endothelial cells that have an upregulation of the lipoprotein receptor-related protein-1. The angiopep-2 peptide ligand (TFFYGGSRGKRNNFKTEEY) has been successfully conjugated to a polyamidoaminedendrimer (PAMAM) with a PEG spacer and studies showed that cellular uptake of the nanoparticles was targeting ligand dose-dependent, and that targeting to the brain was achieved following intravenous delivery [139]. The angiopep targeting system has also been utilised to achieve a therapeutic efficacy in the delivery of PAMAM-PEG-Angiopep/pORF-TRAIL to glial tumours [140]. The administration of these modified nanoparticles yielded an average survival time of 69 days compared to 30 days in the parental PAMAM-PEG/pORF-TRAIL nanoparticle-receiving mice [140].

There are of course numerous examples of systemic targeted delivery employing such ligands. The message that is apparent from all of these studies is that if there is enough information on the expression of a certain receptor, then the incorporation of its targeting ligand into cationic non-viral systems can significantly enhance tumour-targeted accumulation of the nucleic acid.

\subsection{Affibody targeting}

Affibodies are small stable alpha helical proteins that lack disulphide bonds, have a low molecular weight and are essentially designed to mimic the action of antibodies. An original affibody protein scaffold is used as a template from which combinatorial phage libraries can be generated and subsequently ligand-specific affibodies can be selected from using phage display technology. Such protein scaffolds have been generated from bacterial surface receptors such as the IgG binding domains of staphylococcal protein A (SPA). The 58 amino acid $\mathrm{Z}$ domain from staphylococcal protein A (SPA) is one such scaffold that has been used as a template for ligand specific affibodies [141,142].

With respect to cancer targeting, high affinity affibodies have been generated for Human Epidermal Growth Factor Receptor 2 [143], Epidermal Growth Factor Receptor [144], Insulin-like Growth Factor-1 Receptor [145] and Platelet Derived Growth Factor Receptor $\beta$ [146]. Using radio-labelling, all of the affibodies have been shown to accumulate in tumours in vivo with an impressive level of specificity following systemic delivery. The affinity of the affibodies is an important factor and ideally should be in the nanomolar range for effective targeting. For example, the affinity levels of affibody $Z_{\text {HER2:4 }}$ are $50 \mathrm{nmol} / \mathrm{L}$ [147] whereas using a one step affinity maturation process, Orlova and colleagues were able to generate the $Z_{\mathrm{HER2} 2342}$ affibody 
which has an affinity level of $22 \mathrm{pmol} / \mathrm{L}$ [143]. The increased affinity translated into a 4-fold increase in tumour uptake of $Z_{\text {HER2:342 }}$ four hours post-injection with clear contrast in imaging and stability at least up to $24 \mathrm{~h}$ post-injection. With respect to the first generation EGFR affibodies, the affinity was in the $150 \mathrm{nM}$ range [148] which is sub optimal for effective systemic targeting. A similar one step maturation procedure for the EGFR affibody showed that affinity could be significantly improved whereby $Z_{\text {EGFR1907 }}$ had a $K_{d}$ of $5.4 \mathrm{nM}$. Furthermore, there was significant uptake of the indium-111-labeled affibody $Z_{\mathrm{EGFR} 1907}$ in A431 tumours and EGFR-expressing organs in vivo compared to the non-EGFR-affibody $Z_{\text {taq }}$ [144].

Translational applications of these $2^{\text {nd }}$ generation affibodies to date include therapeutic tools for diagnostic and imaging purposes to aid in the identification of molecular drug targets and for the stratification of cancer patient populations. However these highly stable, selective proteins are undoubtedly going to have a huge role in the advancement of targeted non-viral systems in cancer gene therapy. Recently a peptide chimera was designed that consisted of the cell penetrating peptide TAT (T), the DNA condensing motif $\mathrm{Mu}$ and the HER2 affibody (AF). The position of the AF was critical to ensure targeting functionality given that the affibody must be able to fold properly. Prior to synthesis, ITASSER software was employed to predict functionality based upon peptide design with a linker between TAT-MU and AF that was helical and should therefore ensure stability of the domains [149]. Studies with the purified recombinant TAT-Mu-AF showed that this ternary complex could condense DNA, confer protection from degradation by DNase I and offer stability in serum [150]. Using GFP DNA complexed at a 1:8:2 ratio, there was little uptake of the complexes in the HER2-null MDA-MB-231 cell line and green fluorescence in the HER2-expressing MDAMB-453, SK-OV-3 and SK-BR-3 cell lines that was proportional to HER2 receptor density. Furthermore, the complexes were non-toxic and functional when injected intra-tumourally into the HER2 positive MDA-MB-453 breast tumours in vivo [150]. Unfortunately these ternary complexes as yet have not been administered intravenously, which is the ultimate test of functionality, given the range of extracellular barriers previously discussed. Nevertheless, this ternary peptide system holds a lot of promise in the next generation of targeted peptide/ protein delivery systems for non-viral gene therapy.

PEGylated liposomes have also been synthesised conjugated to the $Z_{\text {EGFR:1907 }}$ affibody with a cysteine residue at the C-terminus to form sterically stabilised affibody liposomes (SAL) [151]. Although the SAL system was loaded with the drug mitoxantrone (MTO), other macromolecules such as nucleic acids could be applied to this system. The MTO-SAL nanoparticles were tested for cytotoxicity on EGFR-expressing A431 and MDA-MB-468 cell lines with MCF-7 as a negative control. Results indicated that the MTO-SAL nanoparticles had no effect on the viability of the EGFR-negative MCF-7 cell line (IC50 value $>100 \mu \mathrm{M}$, compared with an IC50 of $18 \mu \mathrm{m}$ for MTO alone), while the EGFR-expressing A431 (2.8 $\mu \mathrm{M})$ and MDA-MB-468 $(6.8 \mu \mathrm{M})$ cell lines were as sensitive to MTO-SAL nanoparticles as they were to MTO only (IC50 $1.3 \mu \mathrm{M}$ and $3 \mu \mathrm{M}$ respectively) [151]. Taken together, these data suggest that SAL specifically delivered its MTO payload to the EGFR-expressing cells, and that EGFR-null cells were protected from MTO-induced cytotoxicity by the SAL vehicle. These studies illustrate that cysteine-modified affibodies can be targeting ligands on liposomal de- 
livery vehicles. Furthermore, by ensuring that receptor-mediated endocytosis occurs via the affibodies, a protective effect is conferred on non-expressing receptor tissue which is highly attractive for the delivery of cytotoxic nucleic acids.

Another example of the use of the $Z_{\text {HER2:342 }}$ affibody [143] is in a multifunctional biopolymer system that comprises several discrete functions [152]. This system consists of a fusogenic peptide (FP) sequence H5WYG [153], a DNA-condensing and endosomolytic domain (DCE) with repeating sequences of arginine and histidine, a M9 nuclear localization domain (NLS) [154] and a C-terminal $Z_{\text {HER2:342 }}$ affibody [143]. What is particularly striking about this delivery system is that the authors have designed it taking into account all of the intracellular barriers, and with the use of discrete motifs, have attempted to overcome each hurdle to successful gene delivery. Engineered within this delivery system is also cathepsin D enzyme substrate (CS) to enable cleavage of the targeting motif from the rest of the vector in late endosomes [152]. The DNA sequence for FP-(DCE)3-NLS-CS-TM was cloned into an inducible expression system and the recombinant biopolymer was expressed and extracted using affinity and size exclusion chromatography [152]. The functionality of each discrete motif was proven and competitive inhibitor binding and transfection studies clearly indicated that the affibody ensured receptor-mediated endocytosis in vitro [152]. Transfection efficiency of $21 \%$ was achieved in the SKOV-3 HER2-expressing cell line, while efficiencies of only 0.1 and $2 \%$ were achieved in the non-expressing PC-3 and MDA-MB-231 prostate and breast cancer cell lines, respectively. In vivo delivery and evaluation of the immune response are critical for the future development of such smart biopolymer systems. Nevertheless, this study illustrates that high affinity affibodies can be functional in recombinant delivery vectors, thus enabling receptor targeting to occur.

\subsection{Transcriptional targeting}

Of course it may not be necessary to have a targeted delivery system to achieve expression of a desired gene in a particular tissue. Many tumours have a differential expression of a particular transcription factor that can be exploited and used to restrict gene expression to a particular site. Several promoters that are either tissue- or tumour-specific have been developed that can circumvent the issues surrounding targeting delivery systems. For example the differential expression in telomerase activity between tumour and normal tissue together with the identification of the minimal components necessary for telomerase activity has enabled the use of the human telomerase reverse transcriptase and the template containing telomerase (hTERT and hTER) promoters to control gene expression. Studies by Dufès et al showed that systemic delivery of polypropylenimedendrimers complexed with a TNFalpha-expressing plasmid under the control of hTER and hTERT gave regression of solid carcinomas in xenografts with $100 \%$ survival with no obvious signs of toxicity [155]. The hTERT promoter has also been used in a dual reporter system with the human alpha fetoprotein (hAFP) promoter to drive expression of MicroRNA-26a (MiR-26a), a known tumour suppressor downregulated in hepatocellular carcinoma (HCC) [156]. The dual promoter system significantly increased MiR-26a expression and reduced viability in vitro and in vivo compared to single promoter or constitutively driven MiR-26a constructs in the HCC cell lines [156]. 
Insulin-like Growth Factor 2 (IGF2) is involved in cellular proliferation and differentiation, but is also overexpressed in a variety of tumours such as bladder carcinoma [157]. IGF2 has a total of four promoters with P3 and P4 promoters responsible for IGF2 expression during foetal and tumour development [158]. P3 and P4 have been utilized to drive expression of the cytotoxic Diphtheria Toxin A gene both as a single promoter system and a dual promoter construct termed P4-DTA-P3-DTA [159]. Part of the rationale for this was related to the differential activation of both $\mathrm{P} 3$ and P4 regulatory sequences in human tumours, so a dual system would ensure induction of DTA in a larger population of tumours. Using PEI as the delivery vehicle, bladder carcinoma studies have revealed that P4-DTA-P3-DTA was superior in vitro and in vivo in both heterotropic and orthotopic bladder tumour models [159]. Similar studies have also been performed in glioma models utilising the cancer-specific H19 promoter in tandem with the P4-IGF2 promoter to selectively control DTA expression [160]. These dual systems have to-date focused on accessible tumours where intratumoural injection would suffice, but only systemic delivery of such systems will fully validate the transcriptional control afforded by these promoters.

Many cancers have the propensity to metastasize to bone, and such tumours acquire osteomimetic characteristics in order to adapt and thrive in the local bone environment. Disseminated bone deposits are resistant to conventional therapies and are particularly difficult to target. Osteocalcin is the most abundant noncollagenous bone matrix protein and is involved in the regulation of bone formation and resorption [161-163]. Osteocalcin is also overe-xpressed in a range of cancers including ovarian, lung, brain, breast and prostate [164-166]. The transcription factor largely responsible for activating the osteocalcin promoter is the master transcription factor RUNX2. RUNX2 is also highly expressed in tumours that metastasise to bone, and therefore widespread activation of the human osteocalcin (hOC) promoter should be achieved, regardless of the heterogeneous tumour microenvironment. The hOC promoter has been utilized to drive inducible nitric oxide synthase (iNOS) expression $[167,168]$. Commercially available liposomes were used as a delivery vehicle for the hOC-iNOS construct. This resulted in exquisite specificity for androgen-independent prostate cancer cells in vitro, coupled with cytotoxicity comparable to that of constitutively expressed iNOS. In vivo data also confirmed the potency of hOC-iNOS gene therapy in a mouse xenograft model of human prostate (PC-3) cancer. Multiple intra-tumoural injections slowed tumour growth dramatically and led to some complete responses. On average, tumour growth was delayed by 59 days compared to vector only controls. This data from these studies supports the premise that tumour-specific promoters can effectively drive iNOS monotherapy giving long term tumour control. Future work within this group is now focused on systemic delivery of hOC-iNOS gene therapy. The hOC promoter has also been delivered systemically to control expression of TK in a replication-defective adenovirus (Ad-hOC-TK) and early viral genes in a replication competent adenovirus (Ad-hOC-E1) [169]. The authors found that vitamins $C$ and $\mathrm{D}_{3}$ significantly increased the activity of the hOC promoter and that triple therapy with Ad-hOC-E1, vitamin $\mathrm{D}_{3}$ and vitamin $\mathrm{C}$ resulted in complete regression in $38 \%$ of renal cell carcinomas in vivo following a single intravenous injection [169]. 
Targeting to a desired tissue is quite often the stumbling block to systemic cancer gene therapy. For the delivery of DNA, targeting can be achieved through the use of promoter sequences. The success of this method of targeting is reliant upon prior knowledge of a difference in transcription factor expression between the target and normal tissue. A delivery system could therefore be designed to condense the DNA, traverse cell membranes, disrupt endosomes and actively transport the payload to the nucleus without the added biophysical complications of having an external targeting motif. Such a delivery system would in theory deliver the DNA to all tissue, but the DNA would only be transcribed and translated where the desired transcription factor is present, namely the target tissue.

\section{Multifunctional delivery}

An understanding of the key biological barriers is critical to the success of a multifunctional delivery vehicle. Perhaps one of the most multifaceted delivery vehicles is the Multifunctional Envelope-type Nano Device MEND system [170]. The authors describe this as a 'programmed packaging' system whereby each part of the system is designed to carry out a specific function in a time-controlled manner. In this system the nucleic acid is condensed with a cationic polymer, wrapped in a lipid envelope which is then functionalised with PEG or other targeting ligands [170]. It is quite clear that PEGylated MEND did have a longer circulation time and was not rapidly cleared from the liver. These are ideal extracellular delivery characteristics, but unfortunately this translated into a much lower gene expression. Therefore circumvention of the 'PEG dilemma' could be achieved via the attachment of targeting ligands to receptors that are known to be over-expressed on tumour cells coupled with the attachment of a cleavable PEG that exploits either intracellular or tumour-specific characteristics. Figure 2 contains a representation of a MEND that highlights some of the nucleic acids that have been delivered and functionalisation strategies that have been used.

The avoidance of an immune response to non-viral strategies can also be greatly improved by use of MENDs as delivery devices. Delivery of pDNA to mice by a MEND resulted in differential expression of almost 1600 genes; PEGylation of the MEND reversed the altered expression of many of these genes. Gene Ontology analysis revealed that in general, the upregulated genes were associated with "immune response," "response to biotic stimulus," "defence response," and related processes. The expression of IL-6, but not IFN $\alpha$ (commonly activated cytokines, as discussed above), were lower in the PEGylated MEND group compared with the non-PEGylated [171]. PEGylation has been shown to limit endosomal escape of gene delivery complexes [172]; inclusion of GALA in the MEND facilitated endosomal escape, and diminished the previously elevated IFN $\alpha$ levels [171]. A MEND functionalised with a PEG-peptide-DOPE conjugate (PPD) was stable in the systemic circulation after intravenous delivery (thereby benefiting from PEG's stabilising characteristic), while it also potently delivered its pDNA cargo to HT1080 fibrosarcoma cells (MMP-rich), but not to HEK293 human embryonic kidney cells (MMP-deficient), thereby avoiding PEG's limiting characteristic [173]. Cleavage of PEG by MMPs facilitates the targeting of tumour tissues which are high in MMPs. 


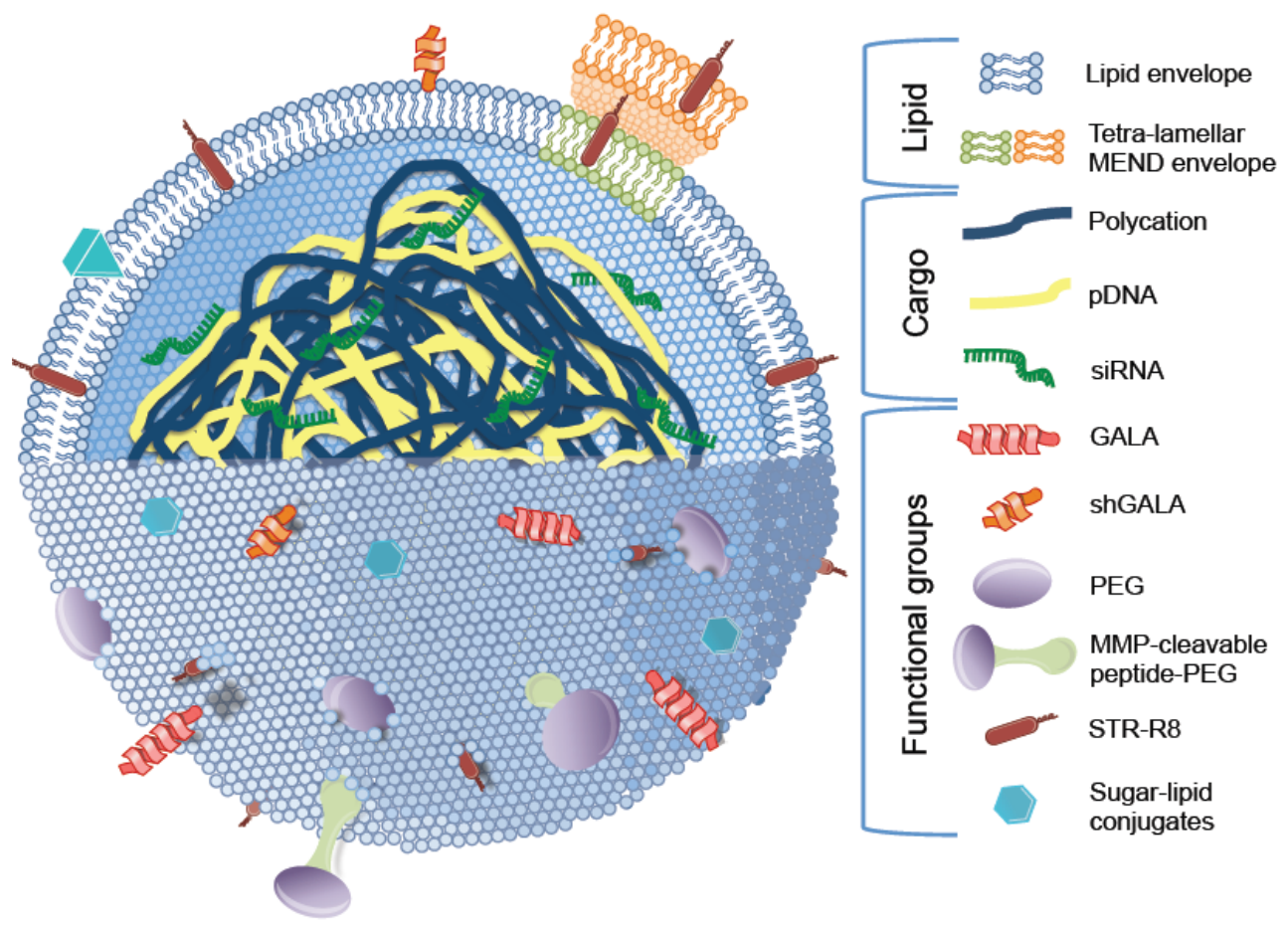

Figure 2. Simplified amalgamation of multifunctional envelope-type nano devices (MENDs) that have been employed for non-viral gene therapy development. pDNA cargoes encoding proteins such as luciferase [173-175] and GFP [176] have been delivered, as well as siRNA targeting luciferase [177,178] and ACTB [179]. MEND polycations are generally PLL $[174,178]$ or protamine $[173,175,176]$. Lipid envelopes usually comprise DOTAP, DOPE and cholesterol $[177,179,180]$, but can also include CHEMS $[174,178]$. Tetra-lamellar MEND envelopes comprise DOPE/cholesterol inner and DOPE/phosphatidic acid outer layers [176]. Functionalisation of MENDS with GALA/short GALA [179], STR-R8 $[174,176,178]$, PEG and MMP-cleavable PEG $[170,173,177]$ and sugar-lipid conjugates [175] have all been reported. Based on [181].

The fundamental limitation associated with non-viral gene therapies is their low transfection ability, compared with viral systems [1]. pDNA condensed using poly-L-lysine and incorporated into a MEND that comprised DOPE, cholesterylhemisuccinate and an octaarginine (R8) peptide (DOPE/CHEMS/STR-R8) transfected HeLa and A549 cells as efficiently as an adenovirus vector. Moreover, the parity of transfection efficiency was achieved without negatively impacting cell viability, as was the case with adenovirus and Lipofectamine $^{\mathrm{TM}}$, and evoked its therapeutic benefit following transdermal delivery in mice [181]. The R8 peptide has been used similarly to deliver proteins directly to cells [182].

A tetra-lamellar MEND (T-MEND) was nano-engineered that envelops the cationically-condensed pDNA in distinct functional layers to target the distinct barrier membranes faced by a nanoparticle. The pDNA-containing core was wrapped in a nucleus-fusogenic lipid membrane, which was in turn wrapped in an endosome-fusogenic lipid membrane that was 
modified with a high density of octa-arginine. Upon endocytosis into the cell, the T-MEND's outermost membrane fuses with the endosomal membrane, releasing the nucleus-fusogenic lipid membrane-bound pDNA core from the endosome into the cytoplasm. The nuclear membrane is then overcome by fusion of the inner nucleus-fusogenic lipid membrane with the nuclear membrane, facilitating transport of the pDNA core into the nucleus. Despite the complexity of the particles, the fully-formed T-MEND produced particles of $163 \mathrm{~nm}$ diameter, and zeta potential of $54.5 \mathrm{mV}$. Unsurprisingly, the T-MEND facilitated impressive pLuciferase delivery in vitro [176]. This exciting T-MEND was further functionalised by addition of fusogenic KALA to the outer and inner membranes, which improved transfection 20-fold [183]. To the authors' knowledge, systemic delivery of multi-layered MENDs is yet to be reported. Caution must be advised, as promising in vitro findings do not always translate into impressive in vivo developments.

\section{Conclusion}

It is apparent that the field of non-viral gene delivery is making significant progress in the quest for the ideal gene delivery vehicle. What is also evident is that the most successful systems are designed to overcome many biological barriers and as a consequence the traditional single function systems are now rendered obsolete. Viruses are nature's perfect delivery vehicle and provide the inspiration to many non-viral gene therapy researchers in the design of state of the art multi-faceted vehicles. Through a greater understanding and appreciation of the biological barriers to systemic gene delivery, non- viral gene therapy researchers are on the cusp of creating a variety of highly efficient vehicles that will revolutionise cancer gene therapy.

\section{Author details}

Cian M. McCrudden and Helen O. McCarthy

School of Pharmacy, Queen's University Belfast, Northern Ireland, UK

\section{References}

[1] Miyata K, Nishiyama N, Kataoka K. Rational design of smart supramolecular assemblies for gene delivery: chemical challenges in the creation of artificial viruses. Chem Soc Rev 2012 Apr 7;41(7):2562-2574.

[2] Temsamani J, Pari GS, Guinot P. Antisense approach for the treatment of cytomegalovirus infection. Expert Opin Investig Drugs 1997 Sep;6(9):1157-1167. 
[3] Ng EW, Shima DT, Calias P, Cunningham ET,Jr, Guyer DR, Adamis AP. Pegaptanib, a targeted anti-VEGF aptamer for ocular vascular disease. Nat Rev Drug Discov 2006 Feb;5(2):123-132.

[4] Thomas CE, Ehrhardt A, Kay MA. Progress and problems with the use of viral vectors for gene therapy. Nat Rev Genet 2003 May;4(5):346-358.

[5] Young LS, Searle PF, Onion D, Mautner V. Viral gene therapy strategies: from basic science to clinical application. J Pathol 2006 Jan;208(2):299-318.

[6] Marshall E. Gene therapy death prompts review of adenovirus vector. Science 1999 Dec 17;286(5448):2244-2245.

[7] Wang T, Upponi JR, Torchilin VP. Design of multifunctional non-viral gene vectors to overcome physiological barriers: dilemmas and strategies. Int J Pharm 2012 May 1;427(1):3-20.

[8] Herweijer H, Wolff JA. Progress and prospects: naked DNA gene transfer and therapy. Gene Ther 2003 Mar;10(6):453-458.

[9] Khalil IA, Kogure K, Akita H, Harashima H. Uptake pathways and subsequent intracellular trafficking in nonviral gene delivery. Pharmacol Rev 2006 Mar;58(1):32-45.

[10] Lam AP, Dean DA. Progress and prospects: nuclear import of nonviral vectors. Gene Ther 2010 Apr;17(4):439-447.

[11] Felgner PL, Gadek TR, Holm M, Roman R, Chan HW, Wenz M, et al. Lipofection: a highly efficient, lipid-mediated DNA-transfection procedure. Proc Natl Acad Sci U S A 1987 Nov;84(21):7413-7417.

[12] Behr JP, Demeneix B, Loeffler JP, Perez-Mutul J. Efficient gene transfer into mammalian primary endocrine cells with lipopolyamine-coated DNA. Proc Natl Acad Sci U S A 1989 Sep;86(18):6982-6986.

[13] Leventis R, Silvius JR. Interactions of mammalian cells with lipid dispersions containing novel metabolizable cationic amphiphiles. Biochim Biophys Acta 1990 Mar 30;1023(1):124-132.

[14] Gao X, Huang L. A novel cationic liposome reagent for efficient transfection of mammalian cells. Biochem Biophys Res Commun 1991 Aug 30;179(1):280-285.

[15] Balazs DA, Godbey W. Liposomes for use in gene delivery. J Drug Deliv 2011;2011:326497.

[16] Kurosaki T, Kitahara T, Teshima M, Nishida K, Nakamura J, Nakashima M, et al. Exploitation of De Novo helper-lipids for effective gene delivery. J Pharm Pharm Sci 2008;11(4):56-67.

[17] Duarte S, Faneca H, Lima MC. Folate-associated lipoplexes mediate efficient gene delivery and potent antitumoral activity in vitro and in vivo. Int J Pharm 2012 Feb 28;423(2):365-377. 
[18] Wang C, Ding C, Kong M, Dong A, Qian J, Jiang D, et al. Tumor-targeting magnetic lipoplex delivery of short hairpin RNA suppresses IGF-1R overexpression of lung adenocarcinoma A549 cells in vitro and in vivo. Biochem Biophys Res Commun 2011 Jul 8;410(3):537-542.

[19] Numata K, Reagan MR, Goldstein RH, Rosenblatt M, Kaplan DL. Spider silk-based gene carriers for tumor cell-specific delivery. Bioconjug Chem 2011 Aug 17;22(8): 1605-1610.

[20] Patil ML, Zhang M, Minko T. Multifunctional triblock Nanocarrier (PAMAM-PEGPLL) for the efficient intracellular siRNA delivery and gene silencing. ACS Nano 2011 Mar 22;5(3):1877-1887.

[21] Liu P, Gou M, Yi T, Qi X, Xie C, Zhou S, et al. The enhanced antitumor effects of biodegradable cationic heparin-polyethyleneimine nanogels delivering HSulf-1 gene combined with cisplatin on ovarian cancer. Int J Oncol 2012 Jul 18.

[22] Chen J, Tian H, Kano A, Maruyama A, Chen X, Park TG. In vitro and in vivo gene delivery using polyethylenimine-poly(hydroxyethyl glutamine) as a non-viral carrier. J Control Release 2011 Nov 30;152 Suppl 1:e134-6.

[23] Li W, Nicol F, Szoka FC,Jr. GALA: a designed synthetic pH-responsive amphipathic peptide with applications in drug and gene delivery. Adv Drug Deliv Rev 2004 Apr 23;56(7):967-985.

[24] Wyman TB, Nicol F, Zelphati O, Scaria PV, Plank C, Szoka FC,Jr. Design, synthesis, and characterization of a cationic peptide that binds to nucleic acids and permeabilizes bilayers. Biochemistry 1997 Mar 11;36(10):3008-3017.

[25] Han J, Il Yeom Y. Specific gene transfer mediated by galactosylated poly-L-lysine into hepatoma cells. Int J Pharm 2000 Jul 20;202(1-2):151-160.

[26] Chen S, Zhuo RX, Cheng SX. Enhanced gene transfection with addition of a cell-penetrating peptide in substrate-mediated gene delivery. J Gene Med 2010 Aug;12(8): 705-713.

[27] Ye SF, Tian MM, Wang TX, Ren L, Wang D, Shen LH, et al. Synergistic effects of cellpenetrating peptide Tat and fusogenic peptide HA2-enhanced cellular internalization and gene transduction of organosilica nanoparticles. Nanomedicine 2012 Aug; 8(6):833-841.

[28] Mangipudi SS, Canine BF, Wang Y, Hatefi A. Development of a genetically engineered biomimetic vector for targeted gene transfer to breast cancer cells. Mol Pharm 2009 Jul-Aug;6(4):1100-1109.

[29] McCarthy HO, Zholobenko AV, Wang Y, Canine B, Robson T, Hirst DG, et al. Evaluation of a multi-functional nanocarrier for targeted breast cancer iNOS gene therapy. Int J Pharm 2011 Feb 28;405(1-2):196-202.

[30] Zhang L, Li L, Hoffmann GA, Hoffman RM. Depth-targeted efficient gene delivery and expression in the skin by pulsed electric fields: an approach to gene therapy of 
skin aging and other diseases. Biochem Biophys Res Commun 1996 Mar 27;220(3): 633-636.

[31] Foldvari M, Babiuk S, Badea I. DNA delivery for vaccination and therapeutics through the skin. Curr Drug Deliv 2006 Jan;3(1):17-28.

[32] Fischer H, Scherz J, Szabo S, Mildner M, Benarafa C, Torriglia A, et al. DNase 2 is the main DNA-degrading enzyme of the stratum corneum. PLoS One 2011 Mar 1;6(3):e17581.

[33] Menck CF, Armelini MG, Lima-Bessa KM. On the search for skin gene therapy strategies of xeroderma pigmentosum disease. Curr Gene Ther 2007 Jun;7(3):163-174.

[34] Warrick E, Garcia M, Chagnoleau C, Chevallier O, Bergoglio V, Sartori D, et al. Preclinical corrective gene transfer in xeroderma pigmentosum human skin stem cells. Mol Ther 2012 Apr;20(4):798-807.

[35] Coulman SA, Barrow D, Anstey A, Gateley C, Morrissey A, Wilke N, et al. Minimally invasive cutaneous delivery of macromolecules and plasmid DNA via microneedles. Curr Drug Deliv 2006 Jan;3(1):65-75.

[36] Zheng D, Giljohann DA, Chen DL, Massich MD, Wang XQ, Iordanov H, et al. Topical delivery of siRNA-based spherical nucleic acid nanoparticle conjugates for gene regulation. Proc Natl Acad Sci U S A 2012 Jul 24;109(30):11975-11980.

[37] Babiuk S, Baca-Estrada ME, Foldvari M, Baizer L, Stout R, Storms M, et al. Needlefree topical electroporation improves gene expression from plasmids administered in porcine skin. Mol Ther 2003 Dec;8(6):992-998.

[38] Lee K, Kim JD, Lee CY, Her S, Jung H. A high-capacity, hybrid electro-microneedle for in-situ cutaneous gene transfer. Biomaterials 2011 Oct;32(30):7705-7710.

[39] Kawabata K, Takakura Y, Hashida M. The fate of plasmid DNA after intravenous injection in mice: involvement of scavenger receptors in its hepatic uptake. Pharm Res 1995 Jun;12(6):825-830.

[40] Mumper RJ, Duguid JG, Anwer K, Barron MK, Nitta H, Rolland AP. Polyvinyl derivatives as novel interactive polymers for controlled gene delivery to muscle. Pharm Res 1996 May;13(5):701-709.

[41] Bitko V, Musiyenko A, Shulyayeva O, Barik S. Inhibition of respiratory viruses by nasally administered siRNA. Nat Med 2005 Jan;11(1):50-55.

[42] Colella P, Cotugno G, Auricchio A. Ocular gene therapy: current progress and future prospects. Trends Mol Med 2009 Jan;15(1):23-31.

[43] Dawson M, Krauland E, Wirtz D, Hanes J. Transport of polymeric nanoparticle gene carriers in gastric mucus. Biotechnol Prog 2004 May-Jun;20(3):851-857.

[44] Wiethoff CM, Middaugh CR. Barriers to nonviral gene delivery. J Pharm Sci 2003 Feb;92(2):203-217. 
[45] Mignet N, Vandermeulen G, Pembouong G, Largeau C, Thompson B, Spanedda MV, et al. Cationic and anionic lipoplexes inhibit gene transfection by electroporation in vivo. J Gene Med 2010 Jun;12(6):491-500.

[46] Liu YP, Tong C, Dispenzieri A, Federspiel MJ, Russell SJ, Peng KW. Polyinosinic acid decreases sequestration and improves systemic therapy of measles virus. Cancer Gene Ther 2012 Mar;19(3):202-211.

[47] Finsinger D, Remy JS, Erbacher P, Koch C, Plank C. Protective copolymers for nonviral gene vectors: synthesis, vector characterization and application in gene delivery. Gene Ther 2000 Jul;7(14):1183-1192.

[48] Kizzire K, Khargharia S, Rice KG. High-affinity PEGylated polyacridine peptide polyplexes mediate potent in vivo gene expression. Gene Ther 2012 Jul 12.

[49] Naeye B, Raemdonck K, Remaut K, Sproat B, Demeester J, De Smedt SC. PEGylation of biodegradable dextran nanogels for siRNA delivery. Eur J Pharm Sci 2010 Jul 11;40(4):342-351.

[50] Xu Z, Smith JS, Tian J, Byrnes AP. Induction of shock after intravenous injection of adenovirus vectors: a critical role for platelet-activating factor. Mol Ther 2010 Mar; 18(3):609-616.

[51] Stone D, Liu Y, Shayakhmetov D, Li ZY, Ni S, Lieber A. Adenovirus-platelet interaction in blood causes virus sequestration to the reticuloendothelial system of the liver. J Virol 2007 May;81(9):4866-4871.

[52] Li L, Wang R, Wilcox D, Zhao X, Song J, Lin X, et al. Tumor vasculature is a key determinant for the efficiency of nanoparticle-mediated siRNA delivery. Gene Ther 2012 Jul;19(7):775-780.

[53] Acharya S, Sahoo SK. PLGA nanoparticles containing various anticancer agents and tumour delivery by EPR effect. Adv Drug Deliv Rev 2011 Mar 18;63(3):170-183.

[54] Tagami T, Suzuki T, Matsunaga M, Nakamura K, Moriyoshi N, Ishida T, et al. Antiangiogenic therapy via cationic liposome-mediated systemic siRNA delivery. Int J Pharm 2012 Jan 17;422(1-2):280-289.

[55] Geis NA, Katus HA, Bekeredjian R. Microbubbles as a vehicle for gene and drug delivery: current clinical implications and future perspectives. Curr Pharm Des 2012;18(15):2166-2183.

[56] Huang Q, Deng J, Xie Z, Wang F, Chen S, Lei B, et al. Effective gene transfer into central nervous system following ultrasound-microbubbles-induced opening of the blood-brain barrier. Ultrasound Med Biol 2012 Jul;38(7):1234-1243.

[57] Gary DJ, Puri N, Won YY. Polymer-based siRNA delivery: perspectives on the fundamental and phenomenological distinctions from polymer-based DNA delivery. J Control Release 2007 Aug 16;121(1-2):64-73. 
[58] Kawakami S, Higuchi Y, Hashida M. Nonviral approaches for targeted delivery of plasmid DNA and oligonucleotide. J Pharm Sci 2008 Feb;97(2):726-745.

[59] Yuan F, Dellian M, Fukumura D, Leunig M, Berk DA, Torchilin VP, et al. Vascular permeability in a human tumor xenograft: molecular size dependence and cutoff size. Cancer Res 1995 Sep 1;55(17):3752-3756.

[60] Capriotti AL, Caracciolo G, Cavaliere C, Foglia P, Pozzi D, Samperi R, et al. Do plasma proteins distinguish between liposomes of varying charge density? J Proteomics 2012 Mar 16;75(6):1924-1932.

[61] Kim WJ, Bonoiu AC, Hayakawa T, Xia C, Kakimoto MA, Pudavar HE, et al. Hyperbranched polysiloxysilane nanoparticles: surface charge control of nonviral gene delivery vectors and nanoprobes. Int J Pharm 2009 Jul 6;376(1-2):141-152.

[62] Hemp ST, Allen MH,Jr, Green MD, Long TE. Phosphonium-containing polyelectrolytes for nonviral gene delivery. Biomacromolecules 2012 Jan 9;13(1):231-238.

[63] Payne CK, Jones SA, Chen C, Zhuang X. Internalization and trafficking of cell surface proteoglycans and proteoglycan-binding ligands. Traffic 2007 Apr;8(4):389-401.

[64] Chen X, Shank S, Davis PB, Ziady AG. Nucleolin-mediated cellular trafficking of DNA nanoparticle is lipid raft and microtubule dependent and can be modulated by glucocorticoid. Mol Ther 2011 Jan;19(1):93-102.

[65] Rehman ZU, Sjollema KA, Kuipers J, Hoekstra D, Zuhorn IS. Nonviral Gene Delivery Vectors Use Syndecan-Dependent Transport Mechanisms in Filopodia To Reach the Cell Surface. ACS Nano 2012 Aug 8.

[66] Mercer J, Schelhaas M, Helenius A. Virus entry by endocytosis. Annu Rev Biochem 2010;79:803-833.

[67] Farhood H, Serbina N, Huang L. The role of dioleoyl phosphatidylethanolamine in cationic liposome mediated gene transfer. Biochim Biophys Acta 1995 May 4;1235(2): 289-295.

[68] Tu Y, Kim JS. A fusogenic segment of glycoprotein $H$ from herpes simplex virus enhances transfection efficiency of cationic liposomes. J Gene Med 2008 Jun;10(6): 646-654.

[69] Subbarao NK, Parente RA, Szoka FC,Jr, Nadasdi L, Pongracz K. pH-dependent bilayer destabilization by an amphipathic peptide. Biochemistry 1987 Jun 2;26(11): 2964-2972.

[70] Haas DH, Murphy RM. Design of a $\mathrm{pH}$-sensitive pore-forming peptide with improved performance. J Pept Res 2004 Jan;63(1):9-16.

[71] Moore NM, Sheppard CL, Barbour TR, Sakiyama-Elbert SE. The effect of endosomal escape peptides on in vitro gene delivery of polyethylene glycol-based vehicles. J Gene Med 2008 Oct;10(10):1134-1149. 
[72] Melchior F, Gerace L. Mechanisms of nuclear protein import. Curr Opin Cell Biol 1995 Jun;7(3):310-318.

[73] Kamiya H, Fujimura Y, Matsuoka I, Harashima H. Visualization of intracellular trafficking of exogenous DNA delivered by cationic liposomes. Biochem Biophys Res Commun 2002 Nov 8;298(4):591-597.

[74] Martin ME, Rice KG. Peptide-guided gene delivery. AAPS J 2007 Feb 9;9(1):E18-29.

[75] Dworetzky SI, Lanford RE, Feldherr CM. The effects of variations in the number and sequence of targeting signals on nuclear uptake. J Cell Biol 1988 Oct;107(4):1279-1287.

[76] Aronsohn AI, Hughes JA. Nuclear localization signal peptides enhance cationic liposome-mediated gene therapy. J Drug Target 1998;5(3):163-169.

[77] Moore NM, Sheppard CL, Sakiyama-Elbert SE. Characterization of a multifunctional PEG-based gene delivery system containing nuclear localization signals and endosomal escape peptides. Acta Biomater 2009 Mar;5(3):854-864.

[78] Hoare M, Greiser U, Schu S, Mashayekhi K, Aydogan E, Murphy M, et al. Enhanced lipoplex-mediated gene expression in mesenchymal stem cells using reiterated nuclear localization sequence peptides. J Gene Med 2010 Feb;12(2):207-218.

[79] Wang HY, Li C, Yi WJ, Sun YX, Cheng SX, Zhuo RX, et al. Targeted delivery in breast cancer cells via iodine: nuclear localization sequence conjugate. Bioconjug Chem 2011 Aug 17;22(8):1567-1575.

[80] Degiulio JV, Kaufman CD, Dean DA. The SP-C promoter facilitates alveolar type II epithelial cell-specific plasmid nuclear import and gene expression. Gene Ther 2010 Apr;17(4):541-549.

[81] Ma K, Hu M, Xie M, Shen H, Qiu L, Fan W, et al. Investigation of polyethyleniminegrafted-triamcinolone acetonide as nucleus-targeting gene delivery systems. J Gene Med 2010 Aug;12(8):669-680.

[82] Mi Bae Y, Choi H, Lee S, Ho Kang S, Tae Kim Y, Nam K, et al. Dexamethasone-conjugated low molecular weight polyethylenimine as a nucleus-targeting lipopolymer gene carrier. Bioconjug Chem 2007 Nov-Dec;18(6):2029-2036.

[83] Griesenbach U, Wilson KM, Farley R, Meng C, Munkonge FM, Cheng SH, et al. Assessment of the nuclear pore dilating agent trans-cyclohexane-1,2-diol in differentiated airway epithelium. J Gene Med 2012 Jul;14(7):491-500.

[84] Wu TL, Ertl HC. Immune barriers to successful gene therapy. Trends Mol Med 2009 Jan;15(1):32-39.

[85] Arruda VR, Favaro P, Finn JD. Strategies to modulate immune responses: a new frontier for gene therapy. Mol Ther 2009 Sep;17(9):1492-1503.

[86] Niidome T, Huang L. Gene therapy progress and prospects: nonviral vectors. Gene Ther 2002 Dec;9(24):1647-1652. 
[87] Gautam A, Densmore CL, Waldrep JC. Pulmonary cytokine responses associated with PEI-DNA aerosol gene therapy. Gene Ther 2001 Feb;8(3):254-257.

[88] Tousignant JD, Gates AL, Ingram LA, Johnson CL, Nietupski JB, Cheng SH, et al. Comprehensive analysis of the acute toxicities induced by systemic administration of cationic lipid:plasmid DNA complexes in mice. Hum Gene Ther 2000 Dec 10;11(18): 2493-2513.

[89] Liu F, Shollenberger LM, Huang L. Non-immunostimulatory nonviral vectors. FASEB J 2004 Nov;18(14):1779-1781.

[90] Krieg AM. CpG motifs in bacterial DNA and their immune effects. Annu Rev Immunol 2002;20:709-760.

[91] de Wolf HK, Johansson N, Thong AT, Snel CJ, Mastrobattista E, Hennink WE, et al. Plasmid CpG depletion improves degree and duration of tumor gene expression after intravenous administration of polyplexes. Pharm Res 2008 Jul;25(7):1654-1662.

[92] Mitsui M, Nishikawa M, Zang L, Ando M, Hattori K, Takahashi Y, et al. Effect of the content of unmethylated CpG dinucleotides in plasmid DNA on the sustainability of transgene expression. J Gene Med 2009 May;11(5):435-443.

[93] Lesina E, Dames P, Flemmer A, Hajek K, Kirchner T, Bittmann I, et al. CpG-free plasmid DNA prevents deterioration of pulmonary function in mice. Eur J Pharm Biopharm 2010 Mar;74(3):427-434.

[94] Whitmore M, Li S, Huang L. LPD lipopolyplex initiates a potent cytokine response and inhibits tumor growth. Gene Ther 1999 Nov;6(11):1867-1875.

[95] Sakurai H, Kawabata K, Sakurai F, Nakagawa S, Mizuguchi H. Innate immune response induced by gene delivery vectors. Int J Pharm 2008 Apr 16;354(1-2):9-15.

[96] Hofman CR, Dileo JP, Li Z, Li S, Huang L. Efficient in vivo gene transfer by PCR amplified fragment with reduced inflammatory activity. Gene Ther 2001 Jan;8(1):71-74.

[97] Darquet AM, Cameron B, Wils P, Scherman D, Crouzet J. A new DNA vehicle for nonviral gene delivery: supercoiled minicircle. Gene Ther 1997 Dec;4(12):1341-1349.

[98] Kobelt D, Schleef M, Schmeer M, Aumann J, Schlag PM, Walther W. Performance of High Quality Minicircle DNA for In Vitro and In Vivo Gene Transfer. Mol Biotechnol 2012 Apr 1.

[99] Zhang C, Liu H, Gao S, Huang W, Wang Z. Polyethylenimine and minicircle DNA based gene transfer. Sheng Wu Gong Cheng Xue Bao 2010 Jun;26(6):772-779.

[100] Vaysse L, Gregory LG, Harbottle RP, Perouzel E, Tolmachov O, Coutelle C. Nucleartargeted minicircle to enhance gene transfer with non-viral vectors in vitro and in vivo. J Gene Med 2006 Jun;8(6):754-763. 
[101] Tolmachov OE. Tightly-wound miniknot vectors for gene therapy: a potential improvement over supercoiled minicircle DNA. Med Hypotheses 2010 Apr;74(4): 702-704.

[102] Yasuda S, Yoshida H, Nishikawa M, Takakura Y. Comparison of the type of liposome involving cytokine production induced by non-CpG Lipoplex in macrophages. Mol Pharm 2010 Apr 5;7(2):533-542.

[103] Yoshida H, Nishikawa M, Yasuda S, Mizuno Y, Toyota H, Kiyota T, et al. TLR9-dependent systemic interferon-beta production by intravenous injection of plasmid DNA/cationic liposome complex in mice. J Gene Med 2009 Aug;11(8):708-717.

[104] Meir YJ, Wu SC. Transposon-based vector systems for gene therapy clinical trials: challenges and considerations. Chang Gung Med J 2011 Nov-Dec;34(6):565-579.

[105] Matsumura Y, Oda T, Maeda H. General mechanism of intratumor accumulation of macromolecules: advantage of macromolecular therapeutics. Gan To Kagaku Ryoho 1987 Mar;14(3 Pt 2):821-829.

[106] Maeda H, Wu J, Sawa T, Matsumura Y, Hori K. Tumor vascular permeability and the EPR effect in macromolecular therapeutics: a review. J Control Release 2000 Mar 1;65(1-2):271-284.

[107] Maeda H, Matsumura Y. EPR effect based drug design and clinical outlook for enhanced cancer chemotherapy. Adv Drug Deliv Rev 2011 Mar 18;63(3):129-130.

[108] Yuan F. Transvascular drug delivery in solid tumors. Semin Radiat Oncol 1998 Jul; $8(3): 164-175$.

[109] Dreher MR, Liu W, Michelich CR, Dewhirst MW, Yuan F, Chilkoti A. Tumor vascular permeability, accumulation, and penetration of macromolecular drug carriers. J Natl Cancer Inst 2006 Mar 1;98(5):335-344

[110] Hobbs SK, Monsky WL, Yuan F, Roberts WG, Griffith L, Torchilin VP, et al. Regulation of transport pathways in tumor vessels: role of tumor type and microenvironment. Proc Natl Acad Sci U S A 1998 Apr 14;95(8):4607-4612.

[111] Matsumura Y, Maeda H. A new concept for macromolecular therapeutics in cancer chemotherapy: mechanism of tumoritropic accumulation of proteins and the antitumor agent smancs. Cancer Res 1986 Dec;46(12 Pt 1):6387-6392.

[112] Ofek P, Fischer W, Calderon M, Haag R, Satchi-Fainaro R. In vivo delivery of small interfering RNA to tumors and their vasculature by novel dendritic nanocarriers. FASEB J 2010 Sep;24(9):3122-3134.

[113] Fang J, Qin H, Nakamura H, Tsukigawa K, Shin T, Maeda H. Carbon monoxide, generated by heme oxygenase-1, mediates the enhanced permeability and retention effect in solid tumors. Cancer Sci 2012 Mar;103(3):535-541.

[114] Tozer GM, Everett SA. Nitric oxide in tumor biology and cancer therapy. Part 2: Therapeutic implications. Clin Oncol (R Coll Radiol) 1997;9(6):357-364. 
[115] Tozer GM, Everett SA. Nitric oxide in tumour biology and cancer therapy. Part 1: Physiological aspects. Clin Oncol (R Coll Radiol) 1997;9(5):282-293.

[116] Wink DA, Vodovotz Y, Cook JA, Krishna MC, Kim S, Coffin D, et al. The role of nitric oxide chemistry in cancer treatment. Biochemistry (Mosc) 1998 Jul;63(7):802-809.

[117] Xu W, Liu LZ, Loizidou M, Ahmed M, Charles IG. The role of nitric oxide in cancer. Cell Res 2002 Dec;12(5-6):311-320.

[118] Worthington J, Robson T, O'Keeffe M, Hirst DG. Tumour cell radiosensitization using constitutive (CMV) and radiation inducible (WAF1) promoters to drive the iNOS gene: a novel suicide gene therapy. Gene Ther 2002 Feb;9(4):263-269.

[119] Worthington J, McCarthy HO, Barrett E, Adams C, Robson T, Hirst DG. Use of the radiation-inducible WAF1 promoter to drive iNOS gene therapy as a novel anti-cancer treatment. J Gene Med 2004 Jun;6(6):673-680.

[120] Bonavida B, Khineche S, Huerta-Yepez S, Garban H. Therapeutic potential of nitric oxide in cancer. Drug Resist Updat 2006 Jun;9(3):157-173.

[121] Wu J, Akaike T, Hayashida K, Okamoto T, Okuyama A, Maeda H. Enhanced vascular permeability in solid tumor involving peroxynitrite and matrix metalloproteinases. Jpn J Cancer Res 2001 Apr;92(4):439-451.

[122] Yasuda H, Yamaya M, Nakayama K, Sasaki T, Ebihara S, Kanda A, et al. Randomized phase II trial comparing nitroglycerin plus vinorelbine and cisplatin with vinorelbine and cisplatin alone in previously untreated stage IIIB/IV non-small-cell lung cancer. J Clin Oncol 2006 Feb 1;24(4):688-694.

[123] Diez S, Migueliz I, Tros de Ilarduya C. Targeted cationic poly(D,L-lactic-co-glycolic acid) nanoparticles for gene delivery to cultured cells. Cell Mol Biol Lett 2009;14(2): 347-362.

[124] Yang DC, Wang F, Elliott RL, Head JF. Expression of transferrin receptor and ferritin H-chain mRNA are associated with clinical and histopathological prognostic indicators in breast cancer. Anticancer Res 2001 Jan-Feb;21(1B):541-549.

[125] Seymour GJ, Walsh MD, Lavin MF, Strutton G, Gardiner RA. Transferrin receptor expression by human bladder transitional cell carcinomas. Urol Res 1987;15(6):341-344.

[126] Kondo K, Noguchi M, Mukai K, Matsuno Y, Sato Y, Shimosato Y, et al. Transferrin receptor expression in adenocarcinoma of the lung as a histopathologic indicator of prognosis. Chest 1990 Jun;97(6):1367-1371.

[127] Kircheis R, Wightman L, Schreiber A, Robitza B, Rossler V, Kursa M, et al. Polyethylenimine/DNA complexes shielded by transferrin target gene expression to tumors after systemic application. Gene Ther 2001 Jan;8(1):28-40.

[128] Lee JH, Engler JA, Collawn JF, Moore BA. Receptor mediated uptake of peptides that bind the human transferrin receptor. Eur J Biochem 2001 Apr;268(7):2004-2012. 
[129] Liu S, Guo Y, Huang R, Li J, Huang S, Kuang Y, et al. Gene and doxorubicin co-delivery system for targeting therapy of glioma. Biomaterials 2012 Jun;33(19):4907-4916.

[130] Hynes NE, MacDonald G. ErbB receptors and signaling pathways in cancer. Curr Opin Cell Biol 2009 Apr;21(2):177-184.

[131] Brand TM, Iida M, Li C, Wheeler DL. The nuclear epidermal growth factor receptor signaling network and its role in cancer. Discov Med 2011 Nov;12(66):419-432.

[132] Wolschek MF, Thallinger C, Kursa M, Rossler V, Allen M, Lichtenberger C, et al. Specific systemic nonviral gene delivery to human hepatocellular carcinoma xenografts in SCID mice. Hepatology 2002 Nov;36(5):1106-1114.

[133] Shir A, Ogris M, Wagner E, Levitzki A. EGF receptor-targeted synthetic doublestranded RNA eliminates glioblastoma, breast cancer, and adenocarcinoma tumors in mice. PLoS Med 2006 Jan;3(1):e6.

[134] Saunders LR, Barber GN. The dsRNA binding protein family: critical roles, diverse cellular functions. FASEB J 2003 Jun;17(9):961-983.

[135] Parker LM, Fierro-Monti I, Reichman TW, Gunnery S, Mathews MB. Double-stranded RNA-binding proteins and the control of protein synthesis and cell growth. Cold Spring Harb Symp Quant Biol 2001;66:485-497.

[136] Schaffert D, Kiss M, Rodl W, Shir A, Levitzki A, Ogris M, et al. Poly(I:C)-mediated tumor growth suppression in EGF-receptor overexpressing tumors using EGF-polyethylene glycol-linear polyethylenimine as carrier. Pharm Res 2011 Apr;28(4): 731-741.

[137] Li Z, Zhao R, Wu X, Sun Y, Yao M, Li J, et al. Identification and characterization of a novel peptide ligand of epidermal growth factor receptor for targeted delivery of therapeutics. FASEB J 2005 Dec;19(14):1978-1985.

[138] Mohammadi Z, Dorkoosh FA, Hosseinkhani S, Gilani K, Amini T, Najafabadi AR, et al. In vivo transfection study of chitosan-DNA-FAP-B nanoparticles as a new non viral vector for gene delivery to the lung. Int J Pharm 2011 Dec 12;421(1):183-188.

[139] Ke W, Shao K, Huang R, Han L, Liu Y, Li J, et al. Gene delivery targeted to the brain using an Angiopep-conjugated polyethyleneglycol-modified polyamidoamine dendrimer. Biomaterials 2009 Dec;30(36):6976-6985.

[140] Huang S, Li J, Han L, Liu S, Ma H, Huang R, et al. Dual targeting effect of Angiopep-2-modified, DNA-loaded nanoparticles for glioma. Biomaterials 2011 Oct;32(28): 6832-6838.

[141] Nilsson B, Moks T, Jansson B, Abrahmsen L, Elmblad A, Holmgren E, et al. A synthetic IgG-binding domain based on staphylococcal protein A. Protein Eng 1987 FebMar;1(2):107-113. 
[142] Nord K, Gunneriusson E, Ringdahl J, Stahl S, Uhlen M, Nygren PA. Binding proteins selected from combinatorial libraries of an alpha-helical bacterial receptor domain. Nat Biotechnol 1997 Aug;15(8):772-777.

[143] Orlova A, Magnusson M, Eriksson TL, Nilsson M, Larsson B, Hoiden-Guthenberg I, et al. Tumor imaging using a picomolar affinity HER2 binding affibody molecule. Cancer Res 2006 Apr 15;66(8):4339-4348.

[144] Friedman M, Orlova A, Johansson E, Eriksson TL, Hoiden-Guthenberg I, Tolmachev $\mathrm{V}$, et al. Directed evolution to low nanomolar affinity of a tumor-targeting epidermal growth factor receptor-binding affibody molecule. J Mol Biol 2008 Mar 7;376(5): 1388-1402.

[145] Li J, Lundberg E, Vernet E, Larsson B, Hoiden-Guthenberg I, Graslund T. Selection of affibody molecules to the ligand-binding site of the insulin-like growth factor-1 receptor. Biotechnol Appl Biochem 2010 Feb 25;55(2):99-109.

[146] Lindborg M, Cortez E, Hoiden-Guthenberg I, Gunneriusson E, von Hage E, Syud F, et al. Engineered high-affinity affibody molecules targeting platelet-derived growth factor receptor beta in vivo. J Mol Biol 2011 Mar 25;407(2):298-315.

[147] Wikman M, Steffen AC, Gunneriusson E, Tolmachev V, Adams GP, Carlsson J, et al. Selection and characterization of HER2/neu-binding affibody ligands. Protein Eng Des Sel 2004 May;17(5):455-462.

[148] Friedman M, Nordberg E, Hoiden-Guthenberg I, Brismar H, Adams GP, Nilsson FY, et al. Phage display selection of Affibody molecules with specific binding to the extracellular domain of the epidermal growth factor receptor. Protein Eng Des Sel 2007 Apr;20(4):189-199.

[149] Gopal V, Guruprasad K. Structure prediction and validation of an affibody engineered for cell-specific nucleic acid targeting. Syst Synth Biol 2010 Dec;4(4):293-297.

[150] Govindarajan S, Sivakumar J, Garimidi P, Rangaraj N, Kumar JM, Rao NM, et al. Targeting human epidermal growth factor receptor 2 by a cell-penetrating peptide-affibody bioconjugate. Biomaterials 2012 Mar;33(8):2570-2582.

[151] Beuttler J, Rothdiener M, Muller D, Frejd FY, Kontermann RE. Targeting of epidermal growth factor receptor (EGFR)-expressing tumor cells with sterically stabilized affibody liposomes (SAL). Bioconjug Chem 2009 Jun;20(6):1201-1208.

[152] Canine BF, Wang Y, Hatefi A. Biosynthesis and characterization of a novel genetically engineered polymer for targeted gene transfer to cancer cells. J Control Release 2009 Sep 15;138(3):188-196.

[153] Midoux P, Kichler A, Boutin V, Maurizot JC, Monsigny M. Membrane permeabilization and efficient gene transfer by a peptide containing several histidines. Bioconjug Chem 1998 Mar-Apr;9(2):260-267. 
[154] Siomi H, Dreyfuss G. A nuclear localization domain in the hnRNP A1 protein. J Cell Biol 1995 May;129(3):551-560.

[155] Dufes C, Keith WN, Bilsland A, Proutski I, Uchegbu IF, Schatzlein AG. Synthetic anticancer gene medicine exploits intrinsic antitumor activity of cationic vector to cure established tumors. Cancer Res 2005 Sep 15;65(18):8079-8084.

[156] Chen L, Zheng J, Zhang Y, Yang L, Wang J, Ni J, et al. Tumor-specific expression of microRNA-26a suppresses human hepatocellular carcinoma growth via cyclin-dependent and -independent pathways. Mol Ther 2011 Aug;19(8):1521-1528.

[157] Mineo R, Fichera E, Liang SJ, Fujita-Yamaguchi Y. Promoter usage for insulin-like growth factor-II in cancerous and benign human breast, prostate, and bladder tissues, and confirmation of a 10th exon. Biochem Biophys Res Commun 2000 Feb 24;268(3):886-892.

[158] Ayesh B, Matouk I, Ohana P, Sughayer MA, Birman T, Ayesh S, et al. Inhibition of tumor growth by DT-A expressed under the control of IGF2 P3 and P4 promoter sequences. Mol Ther 2003 Apr;7(4):535-541.

[159] Amit D, Tamir S, Birman T, Gofrit ON, Hochberg A. Development of targeted therapy for bladder cancer mediated by a double promoter plasmid expressing diphtheria toxin under the control of IGF2-P3 and IGF2-P4 regulatory sequences. Int J Clin Exp Med 2011;4(2):91-102.

[160] Amit D, Matouk IJ, Lavon I, Birman T, Galula J, Abu-Lail R, et al. Transcriptional targeting of glioblastoma by diphtheria toxin-A driven by both H19 and IGF2-P4 promoters. Int J Clin Exp Med 2012;5(2):124-135.

[161] Hauschka PV, Wians FH,Jr. Osteocalcin-hydroxyapatite interaction in the extracellular organic matrix of bone. Anat Rec 1989 Jun;224(2):180-188.

[162] Ducy P, Desbois C, Boyce B, Pinero G, Story B, Dunstan C, et al. Increased bone formation in osteocalcin-deficient mice. Nature 1996 Aug 1;382(6590):448-452.

[163] Boskey AL, Gadaleta S, Gundberg C, Doty SB, Ducy P, Karsenty G. Fourier transform infrared microspectroscopic analysis of bones of osteocalcin-deficient mice provides insight into the function of osteocalcin. Bone 1998 Sep;23(3):187-196.

[164] Coleman RE, Mashiter G, Fogelman I, Whitaker KD, Caleffi M, Moss DW, et al. Osteocalcin: a potential marker of metastatic bone disease and response to treatment. Eur J Cancer Clin Oncol 1988 Jul;24(7):1211-1217.

[165] Koeneman KS, Yeung F, Chung LW. Osteomimetic properties of prostate cancer cells: a hypothesis supporting the predilection of prostate cancer metastasis and growth in the bone environment. Prostate 1999 Jun 1;39(4):246-261.

[166] Jung C, Ou YC, Yeung F, Frierson HF,Jr, Kao C. Osteocalcin is incompletely spliced in non-osseous tissues. Gene 2001 Jun 27;271(2):143-150. 
[167] McCarthy HO, Coulter JA, Worthington J, Robson T, Hirst DG. Human osteocalcin: a strong promoter for nitric oxide synthase gene therapy, with specificity for hormone refractory prostate cancer. J Gene Med 2007 Jun;9(6):511-520.

[168] Coulter JA, Page NL, Worthington J, Robson T, Hirst DG, McCarthy HO. Transcriptional regulation of inducible nitric oxide synthase gene therapy: targeting early stage and advanced prostate cancer. J Gene Med 2010 Sep;12(9):755-765.

[169] Johnson NA, Chen BH, Sung SY, Liao CH, Hsiao WC, W K Chung L, et al. A novel targeting modality for renal cell carcinoma: human osteocalcin promoter-mediated gene therapy synergistically induced by vitamin C and vitamin D(3). J Gene Med 2010 Nov;12(11):892-903.

[170] Hatakeyama H, Akita H, Harashima H. A multifunctional envelope type nano device (MEND) for gene delivery to tumours based on the EPR effect: a strategy for overcoming the PEG dilemma. Adv Drug Deliv Rev 2011 Mar 18;63(3):152-160.

[171] Hatakeyama H, Ito E, Yamamoto M, Akita H, Hayashi Y, Kajimoto K, et al. A DNA microarray-based analysis of the host response to a nonviral gene carrier: a strategy for improving the immune response. Mol Ther 2011 Aug;19(8):1487-1498.

[172] Mishra S, Webster P, Davis ME. PEGylation significantly affects cellular uptake and intracellular trafficking of non-viral gene delivery particles. Eur J Cell Biol 2004 Apr; 83(3):97-111.

[173] Hatakeyama H, Akita H, Kogure K, Oishi M, Nagasaki Y, Kihira Y, et al. Development of a novel systemic gene delivery system for cancer therapy with a tumor-specific cleavable PEG-lipid. Gene Ther 2007 Jan;14(1):68-77.

[174] Kogure K, Moriguchi R, Sasaki K, Ueno M, Futaki S, Harashima H. Development of a non-viral multifunctional envelope-type nano device by a novel lipid film hydration method. J Control Release 2004 Aug 11;98(2):317-323.

[175] Masuda T, Akita H, Nishio T, Niikura K, Kogure K, Ijiro K, et al. Development of lipid particles targeted via sugar-lipid conjugates as novel nuclear gene delivery system. Biomaterials 2008 Feb;29(6):709-723.

[176] Akita H, Kudo A, Minoura A, Yamaguti M, Khalil IA, Moriguchi R, et al. Multi-layered nanoparticles for penetrating the endosome and nuclear membrane via a stepwise membrane fusion process. Biomaterials 2009 May;30(15):2940-2949.

[177] Hatakeyama H, Akita H, Ito E, Hayashi Y, Oishi M, Nagasaki Y, et al. Systemic delivery of siRNA to tumors using a lipid nanoparticle containing a tumor-specific cleavable PEG-lipid. Biomaterials 2011 Jun;32(18):4306-4316.

[178] Moriguchi R, Kogure K, Akita H, Futaki S, Miyagishi M, Taira K, et al. A multifunctional envelope-type nano device for novel gene delivery of siRNA plasmids. Int J Pharm 2005 Sep 14;301(1-2):277-285. 
[179] Sakurai Y, Hatakeyama H, Sato Y, Akita H, Takayama K, Kobayashi S, et al. Endosomal escape and the knockdown efficiency of liposomal-siRNA by the fusogenic peptide shGALA. Biomaterials 2011 Aug;32(24):5733-5742.

[180] Hatakeyama H, Ito E, Akita H, Oishi M, Nagasaki Y, Futaki S, et al. A pH-sensitive fusogenic peptide facilitates endosomal escape and greatly enhances the gene silencing of siRNA-containing nanoparticles in vitro and in vivo. J Control Release 2009 Oct 15;139(2):127-132.

[181] Khalil IA, Kogure K, Futaki S, Hama S, Akita H, Ueno M, et al. Octaarginine-modified multifunctional envelope-type nanoparticles for gene delivery. Gene Ther 2007 Apr;14(8):682-689.

[182] Suzuki R, Yamada Y, Harashima H. Efficient cytoplasmic protein delivery by means of a multifunctional envelope-type nano device. Biol Pharm Bull 2007 Apr;30(4): 758-762.

[183] Shaheen SM, Akita H, Nakamura T, Takayama S, Futaki S, Yamashita A, et al. KALA-modified multi-layered nanoparticles as gene carriers for MHC class-I mediated antigen presentation for a DNA vaccine. Biomaterials 2011 Sep;32(26):6342-6350. 